\title{
A holistic, multi-scale dynamic downscaling framework for climate impact assessments and challenges of addressing finer-scale watershed dynamics
}

\author{
Jongho Kim $^{1}$ and Valeriy Y. Ivanov ${ }^{1}$ \\ ${ }^{1}$ Department of Civil and Environmental Engineering \\ University of Michigan, Ann Arbor, MI 48103
}

November 6, 2014

Corresponding author: Jongho Kim, Department of Civil and Environmental Engineering, University of Michigan, Ann Arbor, MI 48103, tel: 734-763-9663, email: kjongho@umich.edu. 


\section{Abstract}

We present a state-of-the-art holistic, multi-scale dynamic downscaling approach suited to address climate change impacts on hydrologic metrics and hydraulic regime of surface flow at the "scale of human decisions" in ungauged basins. The framework rests on stochastic and physical downscaling techniques that permit one-way crossing $10^{6}-10^{0} \mathrm{~m}$ scales, with a specific emphasis on 'nesting' hydraulic assessments within a coarser-scale hydrologic model. Future climate projections for the location of Manchester watershed (MI) are obtained from an ensemble of General Circulation Models of the 3rd phase of the Coupled Model Intercomparison Project database and downscaled to a "point" scale using a weather generator. To represent the natural variability of historic and future climates, we generated continuous time series of 300 years for the locations of 3 meteorological stations located in the vicinity of the ungauged basin. To make such a multi-scale approach computationally feasible, we identified the months of May and August as the periods of specific interest based on ecohydrologic considerations. Analyses of historic and future simulation results for the identified periods show that the same median rainfall obtained by accounting for climate natural variability triggers hydrologically-mediated non-uniqueness in flow variables resolved at the hydraulic scale. An emerging challenge is that uncertainty initiated at the hydrologic scale is not necessarily preserved at smaller-scale flow variables, because of non-linearity of underlying physical processes, which ultimately can mask climate uncertainty. We stress the necessity of augmenting climate-level uncertainties of emission scenario, multi-model, and natural variability with uncertainties arising due to non-linearities in smaller-scale processes.

Keyword: multi-scale, flow regime, coupled model, climate change, stochastic weather generator 


\section{Introduction}

Human societies require services and goods supplied by watershed systems that need to be sustainable, maintain natural structure and function, and continue to meet societal needs in the longterm [Meyerand Pulliam, 1992]. However, the world is undergoing a period of rapid climate change, rarely experienced in the past [IPCC, 2001; 2007]. Thus, assessments of changes in watershed systems in response to climate change have been increasing [Hanson et al., 2012; Safeeqand Fares, 2012; Wangand Alimohammadi, 2012; Beauchamp et al., 2013; Demaria et al., 2013; Lu et al., 2013; Mukundan et al., 2013; Nunes et al., 2013; Patterson et al., 2013; Shen et al., 2013; Teegavarapu, 2013; Wu et al., 2013; Schnorbus et al., 2014].

Water-related processes that are of interests to human societies mostly originate at the watershed level, and therefore physical processes in the above studies have been commonly addressed at the watershed scale. While watershed-scale assessments represent a necessary starting point, a range of processes that represent societal concern are associated with flow and hydrogeomorphic dynamics in channelized areas. Some examples in which watershed scale, hydrologybased models exhibit applicability limitations are (1) the process of flooding (where and how flood wave propagates is of most interest), (2) hydraulic phenomena such as flow discontinuity and backwater effects (e.g., when hydraulic structures such as spillways, weirs, dams, and bridges are constructed), and (3) runoff routing processes in domains of complex topography, slope transitions, and vegetated areas [Kim et al., 2012a; Kim et al., 2012b; Kim et al., 2013; Kim and Ivanov, 2014; Warnock et al., 2014]. Similarity of these examples is that the flow process exhibits characteristics that reveal limitations of hydrology models that mainly use simplified versions of governing equations representing fluid motion. One of the central reasons of limitations to describe the flow process is that commonly used simplified approaches, referred to as the "inertia-free" or the 
"kinematic wave" models, alter the physics of flow waves that should move with finite bidirectional speeds into the waves that either have infinite, bidirectional speed or become unidirectional with a finite speed. Thus, such approximations cannot mimic real physical phenomena such as flow discontinuities, backwater, or wave reflection. A more comprehensive review of the three commonly used routing methods is provided in Warnock et al. [2014].

At the other end of research spectrum, "stream-reach based" numerical models have been often used with the purpose of identifying a more detailed level of flow characterization, i.e., extending beyond the traditional metrics of bulk flow, which can be directly attributed to major impacts on water quality, morphology, and aquatic habitat characteristics. For example, the shear stress or stream power are the most frequently used flow variables in modeling morphological processes [Bagnold, 1966; Woolhiser et al., 1990; Hairsineand Rose, 1992a], while the turbulent kinetic energy, circulation, or vorticity are some of the vital metrics that convey ecological effects of streamflow on aquatic habitat [Crowderand Diplas, 2002; 2006]. However, these models, despite providing excellent results on characterization of the flow regime, have a significant drawback when applied to investigate the impact of future conditions or ungauged basins. In these circumstances, the boundary conditions are unknown at the inlet and outlet of stream reaches. Assuming artificial boundary conditions fails to connect to catchment- and larger-scale information (e.g., climate), and therefore essentially "disengages" channel flow from watershed processes [Milly et al., 2002; Arnell, 2003; Cherkauerand Sinha, 2010].

Understanding and predicting the corresponding shifts across a range of space-time scales at the relevant level of detail is one of the most fundamental, yet poorly quantified challenges facing society today. A particular difficulty is the transformation of uncertainty due to intrinsic nonlinearity of a basin system [Leopoldand Langbein, 1962; Zeheand Sivapalan, 2009]. In order to 
achieve a seamless propagation of climate information into local streamflow variations and capture the uncertainty occurring from coupled hydrologic and hydraulic processes, physically-based modeling of relevant processes at a sufficient detail is needed. Explicit linkage of processes operating at different scales can incorporate the advantages of watershed-based and stream reachbased models, and thus not only enhance accuracy near channelized areas but overcome problems with specifying uncertain boundary conditions. When considered in the context of long-term effects of climate change on such important drivers as precipitation and temperature, perturbations initiated at larger scale will impact hydrological signals originating at the watershed scale. The relevant processes, especially evaporation and runoff, will subsequently alter the flow regime. The flow motion will ultimately influence sediment transport and erosion rates modifying the landscape morphology and affecting aquatic habitat at biologically relevant scales [Crowderand Diplas, 2006; Coulthard et al., 2012; Kim et al., 2013]. Through this "cascade", large scale properties affect smaller-scale characteristics. Therefore, modeling the impacts of climate change on streamflow variations and flow regime requires a holistic approach, i.e., the one that incorporates relevant components from the fields of hydrology and hydraulics.

The capability to simulate processes operating at a range of temporal and spatial scales has been increasing [Ivanov et al., 2004a; Kollet and Maxwell, 2006; Ivanov et al., 2008; Kumar et al., 2009; Mirus et al., 2011; Sulis et al., 2011; Fatichi et al., 2012; Kim et al., 2012b; Chen et al., 2013; Kim et al., 2013; Mirus and Loague, 2013]. The development of coupled models have targeted physical consistency of transferring information from larger-scale drivers to local scale dynamics with a decreasing number of simplifying approximations. Specifically, in our previous work, we developed a coupled hydrology-hydraulics model that can seamlessly handle diverse topographic transitions, including situations where the effects of inertia can become significant [Kim et al., 2012b; Kim et al., 2013]; represent flow cumulating and diverging complexity due to topography, 
unsubmerged vegetation, or rock elements [Kim et al., 2012a]; and extended model applicability to cases with impermeable structures (e.g., rock, vegetation or buildings) requiring a specification of boundary conditions for internal areas [Kim et al., 2012a; Kim et al., 2012b]. However, despite these benefits, the coupled model has been of practical value only at relatively short-time scales (daily to monthly). Such a limitation is similar for other hydraulic models based on explicit numerical schemes that constrain model applicability over longer time periods due to the issues of computational efficiency. To circumvent this difficulty, a multi-scale framework for propagating hydrologic information to flow characteristics is addressed here.

Specifically, a multi-scale modeling approach is used here in which stochastically downscaled climate information $\left(10^{5}-10^{6} \mathrm{~m}\right)$ permits a comparison of watershed-scale $\left(10^{3}-10^{4} \mathrm{~m}\right)$ hydrological regimes for present and future climate conditions, as well as their effect on details of flow hydrodynamics $\left(10^{0}-10^{2} \mathrm{~m}\right)$. Using analogy with climate modeling, the latter is achieved through physical downscaling of hydrologic fluxes. We refer to the concept as "Nested Dynamics Modeling" (NDM), to facilitate generality of such a downscaling approach in the fields of hydrology and ecohydrology.

First, future regional climate information is downscaled using outputs from 12 General Circulation Models (GCMs) of the third phase of the Coupled Model Intercomparison Project (CMIP3) database, the A1B emission scenario of the Special Report on Emission Scenarios (SRES, [Meehl et al., 2005]). Projections of weather variables for 3 nearby meteorological stations are generated for the present/historic and future periods using a stochastic weather generator, Advanced WEather-GENerator (AWE-GEN), combined with the Monte-Carlo simulation to produce an ensemble of alternatives of future climate [Ivanov et al., 2007; Fatichi et al., 2011; 2013]. Next, a number of hydrologic and hydrodynamic metrics of channel flow are resolved by the coupled model, 
TIN (Triangulated Irregular Network) based Real time Integrated Basin Simulator - Flow, Erosion and Sediment Transport (tRIBS-FEaST), designed to address morphological or ecohydrologic applications. The flow process metrics obtained by propagating climate-level information through watershed and channel processes highlight the nonlinearity feature of catchments, and an inherent characteristic of climate impact studies - the uncertainty of assessments. An ungauged watershed located near Manchester, Michigan, where climatic boundary conditions for both present and future periods are not available is used as a case study. This research therefore can be considered as a template for assessments of climate impact on hydrologic and hydraulic regimes in ungauged basins.

\section{Methodology}

\subsection{Stochastic Downscaling and Weather Generator: AWE-GEN}

A stochastic downscaling technique using a weather generator is a suitable tool for this study because weather variables such as solar radiation, relative humidity, and vapor pressure required as input by a comprehensive hydrologic model are not available from GCMs at a relevant scale. This also allows one to overcome a problem of inconsistency in observed data, when dealing with missing values or changes in observational practices. A more detailed description of how global climate information is downscaled to a local scale and how AWE-GEN stochastically generates a range of consistently inter-related weather variables can be found in Fatichi et al. [2011]; an outline of the stochastic downscaling methodology is presented in Fatichi et al. [2013] and Kim et al. [2014]. Only a brief summary is provided below.

Given an ensemble of daily precipitation and monthly temperature series provided from 12 GCMs from the CMIP3 database, AWE-GEN computes a large number of statistics (mean, variance, skewness, and frequency of non-precipitation) for different aggregation intervals (24, 48, 72, and 96 hours) to properly represent high- (seasonal) and low- (interannual) frequency properties of rainfall 
processes for the control $(1961$ - 1990) and future $(2081-2100)$ periods [Fatichi et al., 2011]. The statistical differences between the two time windows are computed for each statistic of the 12 GCMs in either additive (for temperature) or multiplicative (for precipitation) form of "factor of change". The Bayesian weighting averaging approach [Tebaldi et al., 2005] is then employed to derive marginal posterior distributions of the factors of change, facilitating the representation of uncertainties caused by differences in GCM projections and their biases. The posterior marginal probability density functions of factors of change are finally generated by the Markov Chain Monte Carlo (MCMC) simulation for all considered statistics. Any given set of factors of change characterizes a possible (i.e., an "alternative") future climate scenario. Only a single set of factors of change, corresponding to the medians of the marginal distributions representing the "likeliest future" is used in this study to avoid computational challenges associated with the ensemble approach. This however still effectively illustrates the concept of the approach. For the same reason, another source of uncertainty due to $\mathrm{CO}_{2}$ emission scenarios is not considered here. Among the various SRES emission scenarios, only the A1B scenario is used.

\subsection{Coulped Model: tRIBS-FEaST}

A coupled model integrating hydrologic, hydraulic, and morphologic processes has been successfully developed, verified, and applied to real watersheds [Kim et al., 2012b; Kim et al., 2013]. The hydrology module, the TIN (Triangulated Irregular Network) - Based Real Time Integrated Basin Simulator (tRIBS), is capable of simulating in a fully distributed manner a range of hydrological processes such as canopy interception, evapotranspiration from bare soil and vegetated area, vertical and lateral moisture transfers in subsurface zones, reproducing several runoff production mechanisms (i.e., saturation excess, infiltration excess, perched subsurface stormflow, and groundwater exfiltration), given spatial input of meteorological data, topography, landuse, and 
soil type [Ivanov et al., 2004a; b]. Accounting for these hydrologic processes offers a seamless transition to a model that has input in terms runoff - a model of flow and sediment dynamics. Specifically, the Flow, Erosion, and Sediment Transport (FEaST) simulation component routes the flow using physically modeled wave speeds without separating the regions into hillslope and channel elements. Note that the computed flow does not influence runoff generation, implying that water flowing on surface is not allowed to re-infiltrate even though model formulation permits such a feedback mechanism. The Saint-Venant equations [Leendertse, 1967; Liggett, 1968; Abbott, 1974] are adopted in the conservative form of governing equations within a finite-volume framework. A new reconstruction method for flow variables and wet/dry treatment was developed to resolve numerical issues occurring when overland flow moves over watershed terrain, thereby enabling hydrologic applications [Kim et al., 2012b]. Erosion and sediment transport processes are also simultaneously resolved over the same computational triangular mesh through a combined system of equations. In this study, however, we focus on flow phenomena only, without the representation of erosion and sediment transport dynamics. For further details on how the relevant processes are coupled, how boundary conditions are specified, how neighboring mapping functions among unstructured grid cells are addressed, how the bed slope for the still water condition is numerically balanced, etc., the reader is referred to Kim et al. [2012b, 2013].

\subsection{Model Calibration}

Calibration of a numerical model at a relevant detail is one of the challenging tasks that should precede any model-driven assessment. This is particularly true, if observations suitable for rigorous constraining of physical parameterizations are lacking. The Manchester watershed (see Section 3.1 for a description) used in the study as a template for the development of methodology projecting future conditions is an ungauged basin and thus no observational record of streamflow at 
the outlet or internal points is available. Consequently, a procedure of hydrologic regionalization is required to confirm the consistency of the model behavior [Blöschland Sivapalan, 1995], such as a parametric regression, a nearest neighbor method, or hydrologic similarity methods [Li et al., 2010]. In this study, the parametric regression method based on catchment characteristics is used.

To obtain an appropriate parameter set for the Manchester watershed, we used information from 26 nearby USGS streamflow gauges located within a $100 \mathrm{~km}$ radius (see Table 1 and Fig. 1). The contributing areas of these USGS stations range nearly three orders of magnitude, from 24.2 to $16,394.6 \mathrm{~km}^{2}$. The stream gauges have been in operation over different periods as specified in Table 1. The total number of observed years for all gauge locations is 1,465 years. In our calibration effort for the ungauged Manchester watershed, an implicit assumption is that essential, properly scaled characteristics of the hydrologic regime (such as the degree of coupling of surface and groundwater, climatological, morphological, and soil attributes) when extended over a limited region are "similar" among the 26 selected watersheds, regardless of their sizes. Given the weak variations of climate, topographic, and soil conditions in the vicinity of the Manchester watershed, such an assumption appears to be plausible. Spatially and temporally scaled metrics, such as the "specific discharge" calculated by dividing streamflow by the contributing area of each watershed, are used as representative metrics. If the assumption of similarity of hydrologic regimes is valid, the specific discharges computed for different watersheds should vary within a constrained range of magnitudes.

An important note for this study is that in order to represent historic/“control” hydrologic and hydraulic conditions in this study, simulations are carried for a set composed of 30 AWE-GEN generated ensemble members. Specifically, AWE-GEN is parameterized for each location of meteorological stations in Detroit, Lansing, and Toledo using their respective observational records. The parameterized generator [Fatichi et al., 2011] subsequently produces 10 hourly time-series, 
each 30-year long, representing statistically consistent alternatives of the observed climate, yielding the total duration of 900 years for the three station locations. Such an approach is dictated by the need to better characterize the occurrence of high and low hydrologic extremes that are hard to capture with short observational records. The need and approaches characterizing climate intrinsic variability have been receiving an increased attention in climate change research [Swanson et al., 2009; Deser et al., 2012; Kim et al., 2014] and impact assessment studies of land-surface and hydrologic response [Coulthard et al., 2012; Fatichi et al., 2014].

For a detailed explanation of a general calibration procedure and descriptions of each of the parameters, the reader is referred to the study of Ivanov et al. [2004b; a]. The tRIBS-FEaST model was manually calibrated using the generated historic ensemble set with the final parameter values specified in Tables 2 and 3. As the basin is ungauged and no other relevant information (such as soil moisture or evapotranspiration flux) is available, the calibration procedure targeted to match the median of the ensemble set of simulated specific discharges to the median of discharges obtained for the gaged USGS watersheds. Note that each 30-year simulation is long-term and accounts for the uncertainty of climatic forcing, which is particularly important given the lack of within-basin precipitation data. Therefore, when the simulated long-term median of the study basin regime approaches the "behavioral median" of neighboring basins, this implies that the essential long-term hydrologic characteristics of the study watershed during the control period are adequately captured by the model.

\subsection{Multi-Scale Approach}

The representation of relevant scales in assessment studies plays a pivotal role for end users. The scale issue has received significant attention in a wide range of environmental disciplines [Wood et al., 1990; Beven, 1991; De Vriend, 1991; de Boer, 1992; Avissar, 1995; Blöschland 
Sivapalan, 1995]. When water resource applications are considered, the "turbulence scale" is the smallest scale of interest, relevant for studies investigating the effects of local scour on hydraulic structures or the effects of vorticity on fish habitat [Crowderand Diplas, 2002; Stoesser et al., 2010; Khosronejad et al., 2013]. The "hydraulic scale", spatially spanning $10^{0}-10^{3}$ meters, and temporally attributed to the "event-scale", is often used when one addresses such typical hydraulic problems as urban flooding, dam break, or river morphodynamics. The typical "hydrologic scale" ranges spatially $10^{2}-10^{6}$ meters and has larger temporal scales, extending from few minutes of rainfall-runoff process to tens and hundreds of years that focus on seasonal or interannual trends of streamflow variability. Lastly, the "geologic scale" is of interest in studies of landscape evolution and while relevant spatial scales are also of interest in hydrology, the time dimension extends to millennial scales.

While the representation of the continuity of scales (i.e., "multi-scale") is the most intuitive approach to addressing the propagation of smaller and larger-scale signals and disturbances through watershed systems, this has not been a typical practice. Computational challenges are arguably one of the dominant reasons why the different types of scales, such as, for example, the hydraulic and hydrologic scales, are not typically considered together. The smallest time step associated with a given application determines the overall computational CPU time. The time stepping depends on which numerical scheme is implemented in a given model. For examples, the finite volume method with explicit temporal discretization used in a variety of hydraulic models [Roe, 1981; Delis et al., 2000; Zoppouand Roberts, 2003] has significant advantages in conserving the local volume of a mass and momentum of flow and thus the global volume becomes automatically and perfectly balanced [Godunov, 1959; Roe, 1981; Hirsch, 1990]. Moreover, this method enables retaining sharpness in the discontinuity of curvature of streamlines [Godunov, 1959; Roe, 1981; Hirsch, 1990]. These benefits of physically consistent simulation are however traded off with the limitation 
of computational time that is controlled with to the Courant-Friedrichs-Lewy (CFL) condition. The time steps commonly used in hydraulic applications are generally in the order of seconds. While time stepping in hydrologic applications is also constrained by the limiting processes such as infiltration and runoff generation, the flexibility is generally higher, especially if an adaptive numerical scheme is employed (e.g., [Ivanov et al., 2010]). For example, the simulation of the coupled model, tRIBS-FEaST for a period of 1 month takes nearly the same amount of time as a tRIBS simulation that only involves hydrologic estimation for a 100-year period ( 50 CPU Hours). Therefore, it is practically infeasible to run the coupled tRIBS-FEaST model over the long-term at the hydraulic scales, which however would represent the true multi-scale simulation.

Here, we present an approach to achieving a multi-scale capability that permits one-way propagation of forcing at sub-regional scale $\left(10^{5}-10^{6} \mathrm{~m}\right)$ to watershed processes $\left(10^{3}-10^{4} \mathrm{~m}\right)$, and to physical dynamics at sub- to stream-reach scales $\left(10^{0}-10^{2} \mathrm{~m}\right)$. While the step of stochastic downscaling of climate information has been described elsewhere [Fatichi et al., 2011], the physically resolved transition from coarser space-time scales of watershed hydrology to focused hydraulic characterizations is a novel element, permitting consistent specification of boundary conditions. By drawing an analogy with the concept of Regional Climate Modeling that accepts coarse-scale boundary conditions from global models or reanalysis products as input to resolve finer-scale features of regional effects [McGregor, 1997], we denote the step of physical downscaling as the Nested Dynamics Modeling (NDM) approach, as a general methodology in the fields of hydrology/ecohydrology that transfers coarser-scale boundary conditions to resolve finerscale details. Among the considered types of scales, only the hydrologic and hydraulic scales are explicitly modeled in this study. Specifically, the concept assumes that hydrologic processes are initially pre-simulated with tRIBS, ensuring that rainfall-runoff partition over a long-term is a consistent representation of the hydrologic regime of a basin. Subsequently, a range of "periods of 
interest" that can be meaningful to end-users are identified. Finally, given the same meteorological forcing and pre-determined initial and boundary conditions, both hydrological and hydraulic processes of tRIBS-FEaST are carried out for such periods of interest, thereby also enabling temporal nesting of resolved dynamics. The multi-scale approach facilitated through NDM offers the capability of completing a longer-term simulation using a seamless transfer of temporally varying initial and boundary conditions from hydrologic to hydraulic dynamics. Ensuring such a communication between the models is important for consistent "cascading" of larger-scale information to processes operating at smaller scales. Placing NDM in the context of climate impact assessments allows accounting for uncertainties of climate drivers in metrics of finer-scale processes.

\section{Simulation Setup}

\subsection{Manchester Watershed}

In order to investigate variations of flow regime under climate change conditions, a realworld, ungauged, small-size basin, Manchester watershed located in the state of Michigan (see Fig. 1) is chosen as a case study because the water quality and ecological health of this area have been degraded due to non-point source contributions caused by landuse conversion, such as the loss of wetlands, and an increase of intensive agriculture [River Raisin Watershed Council, 2009]. Most of the basin $(\sim 78 \%)$ exhibits typical slopes of less than $10 \%$, while the rest of the area has somewhat steeper slopes of $10-30 \%$. The area of the watershed is $3.036 \mathrm{~km}^{2}$ and the predominant soil type is silty sand, with 4 textural sub-types that are spatially distributed (see Fig. 2). About $68 \%$ of the middle basin area is covered with shrubs, grasslands, and crops, while about $22 \%$ in its southern part is occupied by forest. Information about vegetation cover and soil type was obtained from the U.S. Geological Survey (USGS) Land Use and Land Cover (LULC) data set and the Soil 
Conservation Service (SCS) Soil Survey Geographic Database (SSURGO). Basin topography and spatial distributions of soils and land uses are shown in Fig. 2. The domain is numerically discretized into a uniform triangular mesh based on $30 \mathrm{~m}$ resolution DEM data, where the number of nodes and triangular cells is 3,670 and 7,299, respectively. The Manning's coefficient for hydraulic routing of 0.03 is used. The time step used for hydrologic processes is $7.5 \mathrm{~min}$, and the time step used for hydraulic routing satisfying the CFL condition is 0.1 sec.

\subsection{Meteorological Forcing}

Since there are no meteorological weather stations monitoring rainfall and meteorological variables in the Manchester watershed, the hourly data from three nearby stations are used instead (available from WebMet [2014]). These meteorological stations are located within a $100 \mathrm{~km}$ radius from the Manchester basin near the cities of Detroit, Lansing, and Toledo, hereinafter abbreviated with DET, LAN, and TLD, respectively. The data provide a number of weather variables such as solar diffuse and direct beam radiation, atmospheric and vapor pressure, cloud cover, and wind speed, as well as rainfall and air temperature for a 30 year period of 1961 to 1990 . However, some of the variables were partly observed on a 3-hour basis or are currently missing. Only a fraction of 30 -year data is used in the study, classified as periods of "good quality" and resulting in 26,18 , and 16 years for DET, LAN, and TLD, respectively. The most important weather variables, i.e., precipitation and temperature, are illustrated in Fig. 3 at a monthly scale. As seen, the cycle of mean monthly temperature averaged over the respective observational periods is consistent for the three locations, while there are slight differences among the locations in terms of seasonality of mean monthly precipitation, but the mean monthly precipitation is overall higher during summer season (Jun. and Aug.) than during winter (Jan. and Feb.). 
Since such observations were obtained for a relatively short period and resulted in discontinuous series, there is a need to ensure that forcings required for modeling of watershed dynamics are representative of the climatic background. Thus, continuous hourly time series were generated with a stochastic weather generator, AWE-GEN, that had been parameterized for each of the weather station locations [Fatichi et al., 2011]. Ten ensemble members, each of which contained 30-year series were generated to represent 300-year stationary climate. Using such long time series allows one to take into account climate internal (natural) variability for the given time interval, as well as to provide a consistent basis for a comparison with simulations representing projections into the future (as explained in the next section). Thus, the top subplots of Fig. 3 also show the simulation results of AWE-GEN for rainfall and temperature for all three locations. A satisfactory performance is observed in terms of reproducing the mean observed weather variables at the monthly scale (Fig. 3a, top panel) and shorter temporal scales (not shown, similar examples are discussed in [Fatichi et al., 2011]). The time series representing the past/historic climate conditions are then used as input to the coupled hydrologic and hydraulic model tRIBS-FEaST.

\subsection{Climate change projections}

Dominant forcings required for assessment simulations of climate change impact need to be "downscaled". A comprehensive analysis of changes caused by possible climate trajectories and an assessment of the associated uncertainties have been demonstrated over a climatic transect of the state of Michigan [Kim et al., 2014]. In this study, rather than investigating "climate-level" uncertainties, we focus on how climate uncertainty propagates through watershed hydrologichydraulic processes. Of all possible climate trajectories offered by the Bayesian Weighted Averaging (BWA), we select the likeliest climate signal, i.e., corresponding to the medians for all factors of change, focusing on one specific moderate emission scenario, A1B. The climate-level 
uncertainty considered is the stochastic (internal) variability, which is accounted for by using 300 years of time series for the future $(2081-2100)$ period that are generated for each of the locations of meteorological stations. The projected monthly precipitation and temperature are illustrated in the bottom panel of Fig. 3. The well-recognized trend of global warming can be easily discerned for all of the locations, while the trend of change in precipitation exhibits an increase during spring season (Mar. to Jun.) but a tendency of decrease during the transition from summer to fall period (Aug. or Sep.). We focus on the end of century period because the decrease in water availability during growing season is exacerbated, as compared to the mid-century, which represents a more illustrative example for this study.

\section{Results}

\subsection{Essential Components of Watershed Hydrologic Regime}

Given an assumption that the nearby gauge locations and the watershed of interest are of similar hydrologic regime and characteristics, we computed the "specific discharge". Fig. 4 shows that the estimates using observations at the USGS gauges indeed appear to cluster within a very limited range, representing a "typical" hydrologic regime of watersheds in southeastern Michigan representative of the historic period. As the result of such hydrological simulations, all of the computed specific discharges are constrained within certain ranges, capable of supporting this assumption and accepting the parameter values specified in Table 2 and 3. Using the calibrated tRIBS-FEaST parameter set, a number of simulations for a set of 30 ensemble members (10 members for each meteorological station location, each 30-year long) representing "alternatives" of the projected climate are carried out for the future period and compared with the simulations of the control period. 
As seen in Fig. 4, hydrological losses for the future period are likely to increase at the annual scale and such a trend is more pronounced during the months of growing season (May-October). This conclusion is not surprising because a comprehensive study of CMIP3 climate projections by Kim et al. [2014] identified trends of growing temperature overlapping with a decreasing trend in precipitation during growing season. However, the result illustrated in Fig. 4 is an explicit confirmation of the thesis of a trend towards hydrologically drier conditions. Climate-level information propagated through a hydrologic system offers a quantifiable range of impact on runoff, accounting for the possible perturbation "dissipation" effects due to seasonal hydrologic storage [Leopoldand Langbein, 1962; Zeheand Sivapalan, 2009].

A multi-scale approach addressed in this study ultimately targets to provide detailed information of flow regime at a hydraulic, stream reach-relevant scale, and thus rigorous, physically sound governing equations and their application at fine temporal scales are used. To make simulations feasible using "conventional" computational power (i.e., an Intel Nehalem/I7 64-bit cluster, http://cac.engin.umich.edu/resources/systems/), we only focus on the period of growing season (May to October), rather than the entire year. One argument supporting this approach is that this season is expected to be vulnerable in terms of water availability (e.g., Kim et al., [2014]). During growing seasons, the months of May and August are of particular interest in the following analyses due to their placement in the context of projected changes. Specifically, for May, precipitation is likely to increase and the temperature increase is mild, and therefore climate change impacts on runoff production are expected to be relatively small (Fig. 3 and Fig. 5). For August, a substantial increase in temperature is expected for the future period, while rainfall is likely to decrease or stay unchanged. The conditions of these two months may have different implications on ecological function of vegetated and aquatic systems, and therefore we develop a monthly-based analysis with a specific emphasis on these two months. 
Fig. 5 and 6 show watershed-scale total monthly runoff and evapotranspiration, and mean soil moisture content averaged over the top $100 \mathrm{~mm}$ of soil column, for the months of May and August. Since the hydrological simulations are carried out using ten, 30-year long projected climate series for each location of meteorological stations, 300 monthly values are depicted for the control and the future periods. It can be noted that (1) the median precipitation (as also inferred from Fig. 3) is projected to increase for the future time window for both DET and LAN in the month of May, while precipitation decreases for all locations in the month of August; (2) the median runoff generally decreases slightly when climate trajectories for LAN and TLD are used for the month of May, and decreases significantly for all 3 locations for August. The case of DET, the month of May, is the only scenario for which runoff is likely to increase; (3) the median evapotranspiration for all cases grows at the rates of about $15 \mathrm{~mm} /$ month in May and about $20 \mathrm{~mm} / \mathrm{month}$ in August; (4) the median soil moisture content averaged over top $100 \mathrm{~mm}$ of soil column is likely to become lower: about $1.5 \%$ for May and about $3.5 \%$ for August (see also Table 4). Overall hydrologic response over the two months is that runoff is likely to be reduced in the future period, except for the case of DET, the month of May, where the effect of increasing precipitation compensates the loss of moisture caused by increasing temperature and evapotranspiration potential.

Another interesting feature illustrated by these figures is a non-unique characteristic of runoff production. The range of runoff volumes produced in the two considered months over a range of ensemble years is widely spread, with the variability reaching up to $\sim 2$ orders of magnitude given a precipitation input. While the inference is not novel (Smith et al., 2004; Buda et al., 2009; Mirus et al., 2011), investigating how such an extent of variability initiated at a larger climate-level scale can be dissipated or inflated at much smaller scales of "human decisions" can be considered to be an appropriate task in climate impact assessment studies. We identified two years for each time period (out of the total 300), such that they have a similar amount of rainfall during May or August 
(equal to ensemble median) but significantly different runoff magnitudes (see blue/red symbols in Figs. 5 and 6). Specifically, one of the selected years exhibits the smallest monthly runoff, while the other has maximum runoff, of all of the years that satisfy the criterion of having monthly total precipitation within the interval of the median $\pm 5 \mathrm{~mm}$. They highlight that the hydrologic response can vary significantly in response to the combined effects of initial and forcing conditions (Smith et al., 2004; Buda et al., 2009; Mirus et al., 2011). Initially wet condition of soil moisture combined with rainfall generate a higher volume of runoff, but radiative fluxes, cloudiness, and rainfall intermittency affect the amount of evapotranspiration, thus in the end, controlling the degree of runoff production. For the purpose of an illustrative analysis of the corresponding hydrologic and hydraulic conditions at a finer spatial scale, we focus on these two years and denote them hereinafter as "min" and "max" years.

\subsection{Essential Variables of the Flow Regime}

Spatial distributions of flow variables of depth, velocity, and shear stress are presented in Fig. 7 for the "min" and "max" years for the month of May only (the climate time series for the location of Detroit were used corresponding to the control period). The figure illustrates how the flow drainage pattern can vary given different hydrologic conditions. The instantaneous spatial distributions of the figure specifically correspond to the peak time of the hydrograph generated for the simulated month of May. As expected a priori, depths, velocities, and shear stresses are very small in the hillslopes, as compared to the stream network. When switching from "min" to "max" year, the flow depths and the magnitudes of velocity increase, the width of channelized flow expands, the stream network becomes more continuous and pronounced, and the power to perturb soil substrate grows. Throughout most of the stream network of this fairly small domain, the flow is of shallow depth, smaller than $0.1 \mathrm{~m}$, slow velocity, less than $1.0 \mathrm{~m} / \mathrm{s}$, and shear stress, lower than 
$20.0 \mathrm{~kg} / \mathrm{m} / \mathrm{s}^{2}$ (see Fig. 8). It is important to note that such a detailed characterization of flow regime is attained in a physically sound manner, by seamlessly propagating information from climate forcing. The NDM approach allows the computation of accompanying flow variables such as shear stress, stream power, turbulent kinetic energy, vorticity, and circulation, extending beyond the flow primary variables (depth and velocity) that are needed, for example, for carrying out simulations of morphological and ecological processes.

Fig. 8 illustrates the boxplots of flow depth, velocity, and shear stress averaged over the area of stream network in the study basin at the peak flow time. Specifically, the stream network region is approximately determined as computational cells where the simulated flow depths are greater than a threshold magnitude. In this study, the peak of the flow time series for the DET location and the CTL period case (i.e., Fig. 7-(d)) and a threshold depth of $10 \mathrm{~mm}$ were used to identify the channel network. This region of stream network obtained using the above criteria and corresponding to an area of $\sim 13 \%$ of the total watershed area will be used in subsequent analyses. As expected, the trends of flow dynamics depend on the magnitude of runoff production; if runoff increases or decreases in the future, then characteristics of flow are correspondingly affected. However, investigating such possible trends in flow variables at finer stream-reach scale represents another level of challenge due to intrinsic characteristics of watershed system: the nonlinearity [Leopoldand Langbein, 1962; Zeheand Sivapalan, 2009]. Its significance has been emphasized in numerical experiments, as an example, investigating vegetation-mediated impacts on erosion processes of hillslope aspect [Istanbulluoglu et al., 2008; Poulos et al., 2012; Kim et al., 2013], and how the impact of aspect can propagate into non-linear dependencies in hydrological processes, flow, and morphodynamics [Kim et al., 2013]. A comparison of the min and max years, Fig. 8 also indicates that the same coarse temporal scale climatological forcing leads to differences in flow 
characteristics, thereby signifying non-uniqueness of the relationship between the meteorological forcing (precipitation) and the hydraulic variables.

\subsection{Non-linearity of the watershed system}

Previous section points to inherent characteristics of a watershed system, the non-uniqueness, and a spatial representation of the non-uniqueness on stream networks, which needs to be dealt with when smaller-scale, nonlinear dynamics are of concern in climate impact assessment studies. It is initiated at the level of hydrological processes and propagates into flow processes in stream network. This section further addresses the non-linearity of the basin response through a comparison of the two analysis time windows. As discussed, explicit simulations over the time span of 300 years that could address the associated uncertainty entirely are avoided due to the computational burden.

Instead, several years/months are identified for a comparison.

As an example illustrating the range of possible conditions inferred for future "median climate", Fig. 9 shows "runoff duration curves" that are computed based on the simulated hourly instantaneous runoff rate for each month. Subsequently, 300 curves (300 light blue/red lines in Fig. 9) are obtained for the two analysis periods, the months of May and August. In order to illustrate the range of possible variations in the monthly low, median, high, and maximum monthly hydrologic conditions, hourly runoff rates corresponding to 5/50/95 percentiles of non-exceedance probability and the maximum of each duration curve are obtained. For each of these statistical metrics, the extracted 300 points are drawn in the form of duration curves (four dark blue/red lines representing the four selected statistics). Note that while each runoff duration curve represents information at the scale of a period of a single month, the selected statistics represent fluctuations of low, median, and high flow conditions due to interannual variations. 
As seen in Fig. 9, the differences of the four statistics (three selected percentiles and maximum) between the two time periods (CTL and FUT) are very marginal for the month of May, as compared to the month of August for which changes are observed for the entire range of flow conditions: low to maxima. These differences are more significant when lower percentiles are considered. In contrast, the differences among the three locations appear to be negligible (for both of the months). Such an analysis of runoff duration curves confirms that significant disturbances of hydrologic regime can be projected for the month of August, while comparatively small changes are expected in the future for the month of May. As such, the month of August is projected to have ecologically unfavorable condition due to a considerable drop in surface water supply. This provides an "informed basis" for the following narrowed down analyses that will only focus on a single combination: the month of August, using the climate conditions of Toledo (Fig. 9-(f)).

For the purpose of detailed analyses of hydrologic and hydraulic conditions at a finer spatial scale through the coupled simulations with tRIBS-FEaST, we identify years corresponding to the 10 , 50, and 90 non-exceedance percentiles of maximum monthly runoff (marked as 6 circles on the thickest blue/red lines in Fig. 9). These percentiles correspond to low, median, and high conditions of the highest monthly runoff, and therefore represent 'upper envelopes' of channel flow conditions: they describe 'wet extremes' (90\%), 'average extremes' (50\%), and 'dry extremes' (10\%), which nonetheless are at the ecologically favorable end of possible outcomes, since the hydrologic dynamics are projected to have a tendency towards drying for the month of August.

Fig. 10 demonstrates a comparison of hydraulic characteristics between the control and future periods for seven variables. Specifically, these are runoff peak $(R P)$ during the selected months; metrics averaged over the stream network (as defined previously) at the times of the peak flow $(F P)$ corresponding to a given $R P$ : flow depth $(F D)$, velocity $(F V)$, and shear stress $(F S)$; peak 
flow discharge (FP); and 5-day mean low (5dLow) and high (5dHigh) flows. The first five variables are computed at the times corresponding to the selected runoff rate percentiles (shown as circles in Fig. 9f) while the latter two variables are calculated as values corresponding to the $10,50,90$ th percentiles of 300, 5-day mean low/high flows, respectively. The hydrologic metrics of runoff peak and 5-day flows represent longer monthly and larger watershed scales, while the flow hydraulic characteristics are representative of relatively shorter instantaneous and smaller stream reach scale. The two boxplots containing information corresponding to the three selected percentiles are compared for the time windows corresponding to historic and future conditions. For example, a comparison of values corresponding to the 50 percentile (the middle lines of each box in Fig. 10) for the CTL and FUT periods shows that, about $86 \%$ of reduction in $R P$ in the future period triggers about $66 \%$ and $93 \%$ of decreases in $F V$ and $F P$. Although these values can vary due to uncertainties of future climate information, initial condition, and a range of parameter values, the different levels of climate impacts inferred for these variables is mainly because of the non-linearity of basin response and flow dynamics. This can also be noticed by comparing the range of $F V$ (i.e., magnitude of the bar) with that of $F P$, where the latter is much larger, implying that uncertainties of variations in flow velocity $(F V)$ for the highest flows in August are smaller than uncertainties of the corresponding outlet discharges $(F P)$.

\section{Discussion and Conclusions}

We present a holistic, multi-scale approach to investigate the impact of climate change on an ungauged watershed located in the lower region of Michigan. The multi-scale modeling approach refers to the capability of addressing a range of scales, i.e., by downscaling information from driving climatological factors $\left(10^{5}-10^{6} \mathrm{~m}\right)$ to watershed hydrology $\left(10^{3}-10^{4} \mathrm{~m}\right)$, followed by a seamless propagation of the hydrological dynamics into spatially-varying flow regime and 
streamflow variations $\left(10^{0}-10^{2} \mathrm{~m}\right)$. The associated spatiotemporal scales thus extend from the scale of climate model resolution, to the "scale of human decisions", such as the scales of water resources management, control, and design. The novelty of this study is that once the meteorological forcings are provided, a series of nested physical model simulations representing catchment hydrology and stream reach hydraulics (i.e., nested dynamics) can be simultaneously carried out through a coupled model, tRIBS-FEaST, and the relative impacts as well as amplification or dampening of input variability can be explicitly addressed. The approach is sufficiently generic and can therefore be applicable to any ungauged basin.

Information on future climate for the location of the Manchester watershed was downscaled using projections of daily precipitation and monthly temperature from 12 different GCMs provided by the CMIP3 database. The climate-scale information was then downscaled to a "point" scale with the AWE-GEN weather generator that relies on factors of change obtained from marginal distributions through the Bayesian Weighted Averaging method and the Markov Chain Monte Carlo technique. Using the median factors of change for the A1B emission scenario only, the continuous time series of 300 years were generated for the locations of meteorological stations in Detroit, Lansing, and Toledo. Thus, among several possible climate projection uncertainties, only the uncertainty related to climate internal variability was addressed in this study.

To make the multi-scale approach computationally feasible, we ran the coupled model twice for the period of 900-year generated time series of (300 years $\times 3$ locations) for the control period (1961 - 1990) and once for the future (2081 - 2100) time window. The first simulation run was done with the hydrological model (tRIBS) only, for the purpose of calibration to determine a representative historic hydrologic regime and in order to identify periods that are of specific interest for analysis of channel hydraulic conditions. The latter were identified as the months of May and 
August, which represented the periods for which little or significant changes in hydrology are projected for the future. A more specific focus on August conditions that have ecological significance due to projected decline in runoff narrowed down the scope to contrasting examples of hydrologic and hydraulic behaviors.

One of the challenges in any watershed assessments is the non-linearity of basin response to disturbances. In order to illustrate the challenge, we identified low, median, and high conditions of the maximum monthly runoff production rate, so that the changes in the corresponding flow characteristics can be investigated. We carried out simulations for the identified periods of specific conditions with the fully coupled model, tRIBS-FEaST.

Analyses of the results for the control and future periods highlight non-linear and nonunique characteristics of watershed systems. Specifically, the same median rainfall obtained by accounting for climate natural variability (which is vital for impact assessment of climate change [Swanson et al., 2009; Deser et al., 2012; Fatichi et al., 2014; Kim et al., 2014]) triggers hydrologically-mediated non-uniqueness, and non-uniqueness of flow variables resolved at the hydraulic scale. The effect is likely due to temporal distribution of rainfall, soil moisture conditions and variability of meteorological conditions that define evapotranspiration flux, such as wind speed, radiation, relative humidity and temperature. Such non-uniqueness has been addressed previously (Smith et al., 2004; Buda et al., 2009; Mirus et al., 2011) but an emphasis here is on challenges of 'deciphering' the response of watershed processes in an impact assessment study at smaller streamreach (hydraulic) scale.

The variability initiated at the hydrologic scales can either become amplified or dwindle when propagating through processes at smaller scale. The effects of the hydrologic input (runoff) on the variability of flow regime are different depending on what type of flow metrics is considered. 
As an example, a comparison of values corresponding to the 50th percentile of August maxima flows in the CTL and FUT periods shows that a $86 \%$ of reduction in runoff peak $(R P)$ can trigger $66 \%$ and $93 \%$ of decreases in flow volume $(F V)$ and flow peak discharge $(F P)$, respectively. Of course, the metric-specific variability may vary not only because numerous uncertainties affect the results, such as imperfect projections by climate models, limitations of the downscaling methodology and in the representation of hydrologic-hydraulic physical processes, and the lack of observations for model confirmation. This is also because only a limited analysis is presented here, while a more comprehensive study should have included a more complete characterization of flow conditions across a range of exceedance probabilities (i.e., not just 10/50/90 percentiles).

Nevertheless, another level of uncertainty is worth of further attention, when addressing finer scale catchment dynamics in climate change assessments. We emphasize that beyond the uncertainties of climate SRES scenario, multi-model, and natural variability, we need to add uncertainties associated with non-linearities (and the associated non-uniqueness) of watershed processes, which can ultimately mask climate uncertainty originated at a larger-scale. The importance of the 'cascade' non-linear propagation has been highlighted in erosion and sediment transport studies via the notion of "geomorphic multipliers" [Coulthard et al., 2012]. Consequently, climate change impact assessment studies focusing on finer-scale processes need to appreciate the range of possible uncertainties by providing probabilistic information with the assessment.

Some processes that are important were not fully addressed in this study. (1) No consideration of spatial variability of roughness although one may use look-up tables in numerous handbooks for estimating the roughness. The question here is whether the values obtained from an empirical table are sufficiently representative of the actual resistance to overland flow in a realworld watershed. Hydraulic resistance to overland flow is highly influenced by vegetation cover fraction and the amount of larger sediment elements (e.g., rock, boulder) as well as flow rate or 
slope [Kim et al., 2012a]. More accurate, spatially-distributed evaluation of the resistance coefficient was not carried out because of limited information, even though representing fractions of partially-submerged obstacles (e.g., vegetation and debris) can yield approximate absolute impact on resistance [Kim et al., 2012a]. We contend that unless one can quantify this additional resistance with a high accuracy, spatially distributed roughness coefficients will result in uncertainty as large as that obtained using spatially uniform roughness. Thus, we preferred to not introduce spatial variations in the Manning's n and use a lumped value. (2) Due to inevitable constraints due to computational power and terrain DEM availability, a relatively coarser resolution was used and microtopographic features (e.g., rills or streams) occurring inside $450 \mathrm{~m}^{2}$ computational grid cells were ignored, even though solutions for subgrid parameterizations are available [e.g., Hairsineand Rose, 1992b]. (3) Our calibration efforts are certainly minimal in this study and mainly focused on the amount of the basin runoff/yield. This is surely related to the lack of observational data: not only the basin of focus is ungaged, there are no experimental watersheds in MI and the only type of information available is streamflow. More sound assessment of model performance skill requires substantially larger data availability (e.g., soil moisture, groundwater table, bedrock depth, evapotranspiration, etc.). We contend though that in the context of this study, the exactness of model skill is inferior to the methodological novelty of the outlined approach. The interpretation of the results of the application relative to the two time periods offers reasonable inferences as compared to the results obtained with a relatively simple model with an intensive calibration. This is because our model accounts for non-linearity in processes. Again, the manuscript emphasizes how variability initiated at climate-level scale can propagate through watershed system and is dissipated or inflated at much smaller scales of "human decisions". That is, the model results are best interpreted in a comparative sense, rather than as estimation of actual values. (4) The snowpack dynamics accounting for the energy and mass budgets of snow-covered areas [Rinehart et al., 2008] 
were not addressed as the study deliberately focused on characterization growing season period. Despite these weaknesses, the study expands a conventional, watershed-scale assessment framework to a framework that recognizes multiple scales, focusing on the transition of hydrologic impacts to hydraulic applications in which flow dynamics play a vital role.

In present, observations of streamflow are available at a limited number of measurement locations. A much larger number of entirely ungauged basins whose hydrologic and hydraulic characteristics represent a significant interest to society have little-to-none information on streamflow or flow regime, such as spatially varying distributions of depth, velocity, shear stress, etc. The holistic multi-scale approach presented here allows one to use projected changes in climate forcing at the regional scale and propagate them into hydrological-level processes in the surface and subsurface domains, and subsequently into the regime of streamflow at much finer, stream-reach scales. Furthermore, such an approach can facilitate studies of effects of hydraulic perturbations on variables that are of concern in other disciplines such as channel morphology and ecology that depend on changes in hydrology at the catchment scale.

\section{Acknowledgements}

We acknowledge the modeling groups, the Program for Climate Model Diagnosis and Intercomparison (PCMDI) and the WCRP's Working Group on Coupled Modelling (WGCM) for their roles in making available the WCRP CMIP3 multi-model dataset. Support of this dataset is provided by the Office of Science, U.S. Department of Energy. This study was supported by the NSF Grant EAR 1151443. Ivanov was partially supported by the Visiting Faculty Grant at the Institute of Environmental Engineering, ETH Zürich.

\section{References}


Abbott, M. B. (1974), Continuous flows, discontinuous flows and numerical analysis, Journal of Hydraulic Research, 12(4), 417-467.

Arnell, N. W. (2003), Effects of IPCCSRES emissions scenarios on river runoff: a global perspective, Hydrology and Earth System Sciences, 7(5), 619-641.

Avissar, R. (1995), Scaling of land-atmosphere interactions: An atmospheric modelling perspective, Hydrological Processes, 9(5-6), 679-695.

Bagnold, R. A. (1966), An approach to the sediment transport problem for general physics, United States Geological Survey Professional Paper, 442-I, I1-I37.

Beauchamp, J., R. Leconte, M. Trudel, and F. Brissette (2013), Estimation of the summer-fall PMP and PMF of a northern watershed under a changed climate, Water Resources Research, 49(6), 3852-3862.

Beven, K. (1991), Scale Considerations, in Recent Advances in the Modeling of Hydrologic Systems, edited by D. Bowles and P. E. O'Connell, pp. 357-371, Springer Netherlands.

Blöschl, G., and M. Sivapalan (1995), Scale issues in hydrological modelling: A review, Hydrological Processes, 9(3-4), 251-290.

Buda, A.R., Kleinman, P.J.A., Srinivasan, M.S., Bryant, R.B. and Feyereisen, G.W. (2009) Factors influencing surface runoff generation from two agricultural hillslopes in central Pennsylvania. Hydrological Processes 23(9), 1295-1312.

Chen, L., S. Sela, T. Svoray, and S. Assouline (2013), The role of soil-surface sealing, microtopography, and vegetation patches in rainfall-runoff processes in semiarid areas, Water Resources Research, 49(9), 5585-5599.

Cherkauer, A., and T. Sinha (2010), Hydrologic impacts of projected future climate change in the Lake Michigan region, Journal of Great Lakes Research, 36, 33-50.

Coulthard, T. J., J. Ramirez, H. J. Fowler, and V. Glenis (2012), Using the UKCP09 probabilistic scenarios to model the amplified impact of climate change on drainage basin sediment yield, Hydrol. Earth Syst. Sci., 16(11), 4401-4416.

Crowder, D. W., and P. Diplas (2002), Vorticity and circulation: spatial metrics for evaluating flow complexity in stream habitats, Canadian Journal of Fisheries and Aquatic Sciences, 59(4), 633-645.

Crowder, D. W., and P. Diplas (2006), Applying spatial hydraulic principles to quantify stream habitat, River Research and Applications, 22(1), 79-89.

de Boer, D. H. (1992), Hierarchies and spatial scale in process geomorphology: a review, Geomorphology, 4(5), 303-318.

De Vriend, H. J. (1991), Mathematical modelling and large-scale coastal behaviour, Journal of Hydraulic Research, 29(6), 727-740.

Delis, A. T., C. P. Skeels, and S. C. Ryrie (2000), Evaluation of some approximate Riemann solvers for transient open channel flows, Journal of Hydraulic Research, 38(3), 217-231.

Demaria, E. M. C., E. P. Maurer, B. Thrasher, S. Vicuna, and F. J. Meza (2013), Climate change impacts on an alpine watershed in Chile: Do new model projections change the story?, $J$. Hydrol., 502, 128-138.

Deser, C., A. Phillips, V. Bourdette, and H. Teng (2012), Uncertainty in climate change projections: the role of internal variability, Climate Dynamics, 38(3-4), 527-546.

Fatichi, S., V. Y. Ivanov, and E. Caporali (2011), Simulation of future climate scenarios with a weather generator, Advances in Water Resources, 34(4), 448-467.

Fatichi, S., V. Y. Ivanov, and E. Caporali (2012), A mechanistic ecohydrological model to investigate complex interactions in cold and warm water-controlled environments: 1. Theoretical framework and plot-scale analysis, Journal of Advances in Modeling Earth Systems, 4, M05002. doi:05010.01029/02011MS000086. 
Fatichi, S., V. Y. Ivanov, and E. Caporali (2013), Assessment of a stochastic downscaling methodology in generating an ensemble of hourly future climate time series, Climate Dynamics, 40(7-8), 1841-1861.

Fatichi, S., S. Rimkus, P. Burlando, and R. Bordoy (2014), Does internal climate variability overwhelm climate change signals in streamflow? The upper Po and Rhone basin case studies., Science of the Total Environment, http://dx.doi.org/10.1016/j.scitotenv.2013.1012.1014.

Godunov, S. K. (1959), A difference method for numerical calculation of discontinuous solutions of the equations of hydrodynamics, Math Sbornik, 47(89), 271-306.

Hairsine, P. B., and C. W. Rose (1992a), Modeling water erosion due to overland flow using physical principles: 1. Sheet flow, Water Resources Research, 28(1), 237-243.

Hairsine, P. B., and C. W. Rose (1992b), Modeling water erosion due to overland flow using physical principles: 2. Rill flow, Water Resources Research, 28(1), 245-250.

Hanson, R. T., L. E. Flint, A. L. Flint, M. D. Dettinger, C. C. Faunt, D. Cayan, and W. Schmid (2012), A method for physically based model analysis of conjunctive use in response to potential climate changes, Water Resources Research, 48.

Hirsch, C. (1990), Numerical computation of internal and external flows, John Wiley \& Sons, New York.

IPCC (2001), Climate Change 2001: The Scientific Basis. Contribution of Working Group I to the Third Assessment Report of the Intergovernmental Panel on Climate Change. [Houghton, J.T., Y. Ding, D.J. Griggs, 4 M. Noguer, P.J. van der Linden, X. Dai, K. Maskell, and C.A. Johnson (eds.)]. Cambridge University Press, Cambridge, United Kingdom and New York, NY, USA, 881pp.

IPCC (2007), Climate Change: The Physical Science Basis. In: Solomon, S., Qin, D., Manning, M., Chen, Z., Marquis, M., Avery, K.B., Tignor, M., Miller, H.L. (Eds.). Contribution of Working Group 1 to the Fourth Assessment Report of the Intergovernmental Panel on Climate Change, Cambridge University Press, Cambridge, United Kingdom and New York, NY, USA, pp. 996.

Istanbulluoglu, E., O. Yetemen, E. R. Vivoni, H. A. Gutierrez-Jurado, and R. L. Bras (2008), Ecogeomorphic implications of hillslope aspect: Inferences from analysis of landscape morphology in central New Mexico, Geophysical Research Letters, 35(14).

Ivanov, V. Y., R. L. Bras, and D. C. Curtis (2007), A weather generator for hydrological, ecological, and agricultural applications, Water Resources Research, 43(10).

Ivanov, V. Y., R. L. Bras, and E. R. Vivoni (2008), Vegetation-hydrology dynamics in complex terrain of semiarid areas: 1. A mechanistic approach to modeling dynamic feedbacks, Water Resources Research, 44(3).

Ivanov, V. Y., E. R. Vivoni, R. L. Bras, and D. Entekhabi (2004a), Catchment hydrologic response with a fully distributed triangulated irregular network model, Water Resources Research, 40(11).

Ivanov, V. Y., E. R. Vivoni, R. L. Bras, and D. Entekhabi (2004b), Preserving high-resolution surface and rainfall data in operational-scale basin hydrology: a fully-distributed physicallybased approach, J. Hydrol., 298(1-4), 80-111.

Ivanov, V. Y., S. Fatichi, G. D. Jenerette, J. F. Espeleta, P. A. Troch, and T. E. Huxman (2010), Hysteresis of soil moisture spatial heterogeneity and the "homogenizing" effect of vegetation, Water Resources Research, 46, W09521, doi:09510.01029/02009WR008611.

Khosronejad, A., C. Hill, S. Kang, and F. Sotiropoulos (2013), Computational and experimental investigation of scour past laboratory models of stream restoration rock structures, Advances in Water Resources, 54(0), 191-207. 
Kim, J., and V. Y. Ivanov (2014), On the nonuniqueness of sediment yield at the catchment scale: The effects of soil antecedent conditions and surface shield, Water Resources Research, 50(2), 1025-1045.

Kim, J., V. Y. Ivanov, and N. D. Katopodes (2012a), Hydraulic resistance to overland flow on surfaces with partially submerged vegetation, Water Resources Research, 48, W10540, doi:10510.11029/12012WR012047.

Kim, J., V. Y. Ivanov, and N. D. Katopodes (2013), Modeling erosion and sedimentation coupled with hydrological and overland flow processes at the watershed scale, Water Resources Research, 49, 5134-5154.

Kim, J., V. Ivanov, and S. Fatichi (2014), Climate change and uncertainty assessment over a hydroclimatic transect of Michigan, Climate Dynamics, under review.

Kim, J., A. Warnock, V. Y. Ivanov, and N. D. Katopodes (2012b), Coupled modeling of hydrologic and hydrodynamic processes including overland and channel flow, Advances in Water Resources, 37, 104-126.

Kollet, S. J., and R. M. Maxwell (2006), Integrated surface-groundwater flow modeling: A freesurface overland flow boundary condition in a parallel groundwater flow model, Advances in Water Resources, 29(7), 945-958.

Kumar, M., C. J. Duffy, and K. M. Salvage (2009), A Second-Order Accurate, Finite VolumeBased, Integrated Hydrologic Modeling (FIHM) Framework for Simulation of Surface and Subsurface Flow, Vadose Zone Journal, 8(4), 873-890.

Leendertse, J. J. (1967), Aspects of a computational model for long-period water wave propagation, Memorandum RM-5294-PR. Santa Monica, California: The Rand Corporation.

Leopold, L. B., and W. L. Langbein (1962), The concept of entropy in landscape evolution, United States Geological Survey Professional Paper, 500-A, A1-A20.

Li, M., Q. Shao, L. Zhang, and F. H. S. Chiew (2010), A new regionalization approach and its application to predict flow duration curve in ungauged basins, J. Hydrol., 389(1-2), 137-145.

Liggett, J. A. (1968), Mathematical flow determination in open channels, Journal of the Engineering Mechanics Division - ASCE, 94(EM4), 947-963.

Lu, N., G. Sun, X. Feng, and B. Fu (2013), Water yield responses to climate change and variability across the North-South Transect of Eastern China (NSTEC), J. Hydrol., 481, 96-105.

McGregor, J. L. (1997), Regional climate modelling, Meteorl. Atmos. Phys., 63(1-2), 105-117.

Meehl, G. A., C. Covey, B. McAvaney, M. Latif, and R. J. Stouffer (2005), Overview of the coupled model intercomparison project, Bulletin of the American Meteorological Society, 86(1), 89-93.

Meyer, J. L., and W. M. Pulliam (1992), Modifications of Terrestrial aquatic Interactions by a Changing Climate. In: Global Climate Change and Freshwater Ecosystems, P. Firth and S. G. Fisher (Editors). Springer Verlag. New York, New York, 177-191.

Milly, P. C. D., R. T. Wetherald, K. A. Dunne, and T. L. Delworth (2002), Increasing risk of great floods in a changing climate, Nature, 415(6871), 514-517.

Mirus, B. B., B. A. Ebel, C. S. Heppner, and K. Loague (2011), Assessing the detail needed to capture rainfall-runoff dynamics with physics-based hydrologic response simulation, Water Resources Research, 47, W00H10, doi:10.1029/2010WR009906.

Mirus, B.B. and Loague, K. (2013) How runoff begins (and ends): Characterizing hydrologic response at the catchment scale. Water Resources Research 49(5), 2987-3006.

Mukundan, R., S. M. Pradhanang, E. M. Schneiderman, D. C. Pierson, A. Anandhi, M. S. Zion, A. H. Matonse, D. G. Lounsbury, and T. S. Steenhuis (2013), Suspended sediment source areas 
and future climate impact on soil erosion and sediment yield in a New York City water supply watershed, USA, Geomorphology, 183, 110-119.

Nunes, J. P., J. Seixas, and J. J. Keizer (2013), Modeling the response of within-storm runoff and erosion dynamics to climate change in two Mediterranean watersheds: A multi-model, multi-scale approach to scenario design and analysis, CATENA, 102, 27-39.

Patterson, L. A., B. Lutz, and M. W. Doyle (2013), Climate and direct human contributions to changes in mean annual streamflow in the South Atlantic, USA, Water Resources Research, 49(11), 7278-7291.

Poulos, M. J., J. L. Pierce, A. N. Flores, and S. G. Benner (2012), Hillslope asymmetry maps reveal widespread, multi-scale organization, Geophysical Research Letters, 39(6), L06406.

Rinehart, A. J., E. R. Vivoni, and P. D. Brooks (2008), Effects of vegetation, albedo, and solar radiation sheltering on the solution of snow in the Walles Caldera, New Mexico., Ecohydrology, 1, 253-270.

River Raisin Watershed Council (2009), River Raisin Watershed Management Plan.

Roe, P. L. (1981), Approximate Riemann solvers, parameter vectors, and difference-schemes, Journal of Computational Physics, 43(2), 357-372.

Safeeq, M., and A. Fares (2012), Hydrologic response of a Hawaiian watershed to future climate change scenarios, Hydrological Processes, 26(18), 2745-2764.

Schnorbus, M., A. Werner, and K. Bennett (2014), Impacts of climate change in three hydrologic regimes in British Columbia, Canada, Hydrological Processes, 28(3), 1170-1189.

Shen, C., J. Niu, and M. S. Phanikumar (2013), Evaluating controls on coupled hydrologic and vegetation dynamics in a humid continental climate watershed using a subsurface- land surface processes model, Water Resources Research, 49(5), 2552-2572.

Smith, M.B., Koren, V.I., Zhang, Z., Reed, S.M., Pan, J.-J. and Moreda, F. (2004) Runoff response to spatial variability in precipitation: an analysis of observed data. Journal of Hydrology 298(1-4), 267-286.

Stoesser, T., S. J. Kim, and P. Diplas (2010), Turbulent Flow through Idealized Emergent Vegetation, Journal of Hydraulic Engineering-Asce, 136(12), 1003-1017.

Sulis, M., C. Paniconi, C. Rivard, R. Harvey, and D. Chaumont (2011), Assessment of climate change impacts at the catchment scale with a detailed hydrological model of surfacesubsurface interactions and comparison with a land surface model, Water Resources Research, 47(1), W01513.

Swanson, K. L., G. Sugihara, and A. A. Tsonis (2009), Long-term natural variability and 20th century climate change, Proceedings of the National Academy of Sciences, 106(38), 1612016123.

Tebaldi, C., R. L. Smith, D. Nychka, and L. O. Mearns (2005), Quantifying uncertainty in projections of regional climate change: A Bayesian approach to the analysis of multimodel ensembles, Journal of Climate, 18(10), 1524-1540.

Teegavarapu, R. S. V. (2013), Climate change-sensitive hydrologic design under uncertain future precipitation extremes, Water Resources Research, 49(11), 7804-7814.

Wang, D., and N. Alimohammadi (2012), Responses of annual runoff, evaporation, and storage change to climate variability at the watershed scale, Water Resources Research, 48.

Warnock, A., J. Kim, V. Ivanov, and N. Katopodes (2014), Self-Adaptive Kinematic-Dynamic Model for Overland Flow, Journal of Hydraulic Engineering, 140(2), 169-181.

WebMet (2014), The Meteorological Resource Center, www.webmet.com.

Wood, E. F., M. Sivapalan, and K. Beven (1990), Similarity and scale in catchment storm response, Reviews of Geophysics, 28(1), 1-18. 
Woolhiser, D. A., R. E. Smith, and D. C. Goodrich (1990), KINEROS, A kinematic runoff and erosion model: Documentation and user manual, Rep. ARS-77, Agricultural Research Service, USDA, Washington, D. C., 130.

Wu, J. Y., J. R. Thompson, R. K. Kolka, K. J. Franz, and T. W. Stewart (2013), Using the Storm Water Management Model to predict urban headwater stream hydrological response to climate and land cover change, Hydrology and Earth System Sciences, 17(12), 4743-4758.

Zehe, E., and M. Sivapalan (2009), Threshold behaviour in hydrological systems as (human) geoecosystems: manifestations, controls, implications, Hydrology and Earth System Sciences, 13(7), 1273-1297.

Zoppou, C., and S. Roberts (2003), Explicit Schemes for Dam-Break Simulations, Journal of Hydraulic Engineering, 129(1), 11-34. 
Table 1. A list of streamflow gauges located within $100 \mathrm{~km}$ radius of the Manchester watershed. The second column is the hydrologic unit number, as classified by the USGS, the fourth column is the upstream contributing area corresponding to each gauge, and the last column refers to the period of observations in years. The total number of the observed years is 1,465 .

\begin{tabular}{|c|c|c|c|c|c|c|}
\hline & Hydr. Unit & Location & $A\left[\mathrm{~km}^{2}\right]$ & Latitude & Longitude & Years \\
\hline 1 & 04096405 & St. Joseph River at Burlington, MI & 533.5 & $42^{\circ} 06^{\prime} 11^{\prime \prime}$ & $85^{\circ} 04^{\prime} 48^{\prime \prime}$ & 50 \\
\hline 2 & 04096515 & South Branch Hog Creek near Allen, MI & 126.1 & $41^{\circ} 56^{\prime} 55^{\prime \prime}$ & $84^{\circ} 49^{\prime} 40^{\prime \prime}$ & 43 \\
\hline 3 & 04103500 & Kalamazoo River at Marshall, MI & 1162.9 & $42^{\circ} 15^{\prime} 53^{\prime \prime}$ & $84^{\circ} 57^{\prime} 50^{\prime \prime}$ & 44 \\
\hline 4 & 04109000 & Grand River at Jackson, MI & 450.7 & $42^{\circ} 17^{\prime} 01^{\prime \prime}$ & $84^{\circ} 24^{\prime} 32^{\prime \prime}$ & 77 \\
\hline 5 & 04111000 & Grand River near Eaton Rapids, MI & 1712.0 & $42^{\circ} 32^{\prime} 05^{\prime \prime}$ & $84^{\circ} 37^{\prime} 23^{\prime \prime}$ & 48 \\
\hline 6 & 04111379 & Red Cedar River near Williamston, MI & 422.2 & $42^{\circ} 40^{\prime} 59^{\prime \prime}$ & $84^{\circ} 13^{\prime} 09^{\prime \prime}$ & 22 \\
\hline 7 & 04112000 & Sloan Creek near Williamston, MI & 24.2 & $42^{\circ} 40^{\prime} 33^{\prime \prime}$ & $84^{\circ} 21^{\prime} 50^{\prime \prime}$ & 58 \\
\hline 8 & 04112500 & Red Cedar River at East Lansing, MI & 919.4 & $42^{\circ} 43^{\prime} 38^{\prime \prime}$ & $84^{\circ} 28^{\prime} 41^{\prime \prime}$ & 82 \\
\hline 9 & 04113000 & Grand River at Lansing, MI & 3185.7 & $42^{\circ} 45^{\prime} 02^{\prime \prime}$ & $84^{\circ} 33^{\prime} 19^{\prime \prime}$ & 82 \\
\hline 10 & 04161000 & Clinton River at Auburn Hills, MI & 318.6 & $42^{\circ} 38^{\prime} 00^{\prime \prime}$ & $83^{\circ} 13^{\prime} 28^{\prime \prime}$ & 36 \\
\hline 11 & 04166000 & River Rouge at Birmingham, MI & 86.2 & $42^{\circ} 32^{\prime} 45^{\prime \prime}$ & $83^{\circ} 13^{\prime} 25^{\prime \prime}$ & 61 \\
\hline 12 & 04166100 & River Rouge at Southfield, MI & 227.7 & $42^{\circ} 26^{\prime} 51^{\prime \prime}$ & $83^{\circ} 17^{\prime} 51^{\prime \prime}$ & 53 \\
\hline 13 & 04166500 & River Rouge at Detroit, MI & 484.3 & $42^{\circ} 22^{\prime} 23^{\prime \prime}$ & $83^{\circ} 15^{\prime} 17^{\prime \prime}$ & 81 \\
\hline 14 & 04167000 & Middle River Rouge near Garden City, MI & 258.7 & $42^{\circ} 20^{\prime} 53^{\prime \prime}$ & $83^{\circ} 18^{\prime} 42^{\prime \prime}$ & 59 \\
\hline 15 & 04168000 & Lower River Rouge at Inkster, MI & 215.5 & $42^{\circ} 18^{\prime} 02^{\prime \prime}$ & $83^{\circ} 18^{\prime} 01^{\prime \prime}$ & 64 \\
\hline 16 & 04170500 & Huron River near New Hudson, MI & 383.3 & $42^{\circ} 30^{\prime} 46^{\prime \prime}$ & $83^{\circ} 40^{\prime} 35^{\prime \prime}$ & 63 \\
\hline 17 & 04172000 & Huron River near Hamburg, MI & 797.7 & $42^{\circ} 27^{\prime} 55^{\prime \prime}$ & $83^{\circ} 48^{\prime} 00^{\prime \prime}$ & 60 \\
\hline 18 & 04173500 & Mill Creek near Dexter, MI & 331.5 & $42^{\circ} 18^{\prime} 01^{\prime \prime}$ & $83^{\circ} 53^{\prime} 54^{\prime \prime}$ & 47 \\
\hline 19 & 04174500 & Huron River at Ann Arbor, MI & 1888.1 & $42^{\circ} 17^{\prime} 13^{\prime \prime}$ & $83^{\circ} 44^{\prime} 02^{\prime \prime}$ & 95 \\
\hline 20 & 04174518 & Malletts Creek at Ann Arbor, MI & 28.2 & $42^{\circ} 15^{\prime} 53^{\prime \prime}$ & $83^{\circ} 41^{\prime} 18^{\prime \prime}$ & 12 \\
\hline 21 & 04175600 & River Raisin near Manchester, MI & 341.9 & $42^{\circ} 10^{\prime} 05^{\prime \prime}$ & $84^{\circ} 04^{\prime} 34^{\prime \prime}$ & 38 \\
\hline 22 & 04176000 & River Raisin near Adrian, MI & 1199.2 & $41^{\circ} 54^{\prime} 17^{\prime \prime}$ & $83^{\circ} 58^{\prime} 51^{\prime \prime}$ & 51 \\
\hline 23 & 04176500 & River Raisin near Monroe, MI & 2698.8 & $41^{\circ} 57^{\prime} 38^{\prime \prime}$ & $83^{\circ} 31^{\prime} 52^{\prime \prime}$ & 74 \\
\hline 24 & 04177000 & Ottawa River at University of Toledo, $\mathrm{OH}$ & 388.5 & $41^{\circ} 39^{\prime} 35^{\prime \prime}$ & $83^{\circ} 36^{\prime} 45^{\prime \prime}$ & 37 \\
\hline 25 & 04184500 & Bean Creek at Powers, OH & 533.5 & $41^{\circ} 39^{\prime} 34^{\prime \prime}$ & $84^{\circ} 14^{\prime} 57^{\prime \prime}$ & 51 \\
\hline 26 & 04193500 & Maumee River at Waterville, $\mathrm{OH}$ & 16394.6 & $41^{\circ} 30^{\prime} 00^{\prime \prime}$ & $83^{\circ} 42^{\prime} 46^{\prime \prime}$ & 77 \\
\hline
\end{tabular}


Table 2. The soil hydraulic and thermal parameters used for Manchester watershed simulations (see Fig. 2)

\begin{tabular}{ccccccccccccc}
\hline Type & Sand/Silt/Clay & $\boldsymbol{K}_{\boldsymbol{s}}$ & $\boldsymbol{\theta}_{\boldsymbol{s}}$ & $\boldsymbol{\theta}_{\boldsymbol{R}}$ & $m$ & $\boldsymbol{\varphi}_{\boldsymbol{B}}$ & $f$ & $\boldsymbol{A}_{\boldsymbol{s}}$ & $\boldsymbol{A}_{\boldsymbol{u}}$ & $\boldsymbol{\eta}^{\prime}$ & $\boldsymbol{k}_{\boldsymbol{s}}$ & $\boldsymbol{C}_{\boldsymbol{s}}$ \\
\hline 1 & $45 / 35 / 20 \%$ & 9.15 & 0.392 & 0.04 & 0.181 & -516 & 0.000725 & 10 & 10 & 50 & 1 & 1000000 \\
2 & $55 / 30 / 15 \%$ & 18.47 & 0.384 & 0.04 & 0.201 & -306 & 0.000785 & 10 & 10 & 50 & 1 & 1000000 \\
3 & $65 / 20 / 15 \%$ & 23.91 & 0.383 & 0.04 & 0.175 & -143 & 0.000813 & 10 & 10 & 50 & 1 & 1000000 \\
4 & $35 / 30 / 35 \%$ & 1.98 & 0.430 & 0.05 & 0.126 & -660 & 0.000613 & 10 & 10 & 50 & 1 & 1000000 \\
\hline
\end{tabular}

$K_{s}:$ Saturated hydraulic Conductivity $[\mathrm{mm} / \mathrm{hr}], \theta_{s}:$ Volumetric soil moisture at saturation $\left[\mathrm{m}^{3} \mathrm{~m}^{-3}\right]$,

$\theta_{R}$ : volumetric residual soil moisture $\left[\mathrm{m}^{3} \mathrm{~m}^{-3}\right], m$ : Pore-size distribution index [-], $\varphi_{B}$ : Air entry bubbling pressure $[\mathrm{mm}], f$ : Conductivity decay parameter $\left[\mathrm{mm}^{-1}\right], A_{s}$ : Anisotropy ratio in the saturated zone [-], $A_{u}$ : Anisotropy ratio in the unsaturated zone [-], $\eta^{\prime}:$ Bedrock depth $[\mathrm{m}], k_{s}$ : Volumetric heat conductivity $[\mathrm{J} / \mathrm{m} / \mathrm{s} / \mathrm{K}], C_{s}$ : Soil heat capacity $\left[\mathrm{J} / \mathrm{m}^{3} \mathrm{~K}\right]$. For details, refer to Ivanov et al. [2004b].

Table 3. The land use or vegetation parameters used in the Manchester watershed (see Fig. 2)

\begin{tabular}{ccccccccccccc}
\hline Land use type & $a$ & $b 1$ & $P$ & $S$ & $K$ & $b 2$ & $A l$ & $h$ & $K t$ & $R s$ & $V$ & $L A I$ \\
\hline Urbanized area & 0.0 & 0.2 & 0.01 & 2.0 & 0.12 & 1.0 & 0.1 & 0.1 & 0.5 & 500 & 0.2 & 1.8 \\
Forest & 0.5 & 0.2 & 0.25 & 0.5 & 0.12 & 4.0 & 0.2 & 10 & 0.5 & 100 & 0.95 & 5.5 \\
Shrub, Grassland, Crops & 0.5 & 0.2 & 0.25 & 0.4 & 0.12 & 4.0 & 0.2 & 1 & 0.5 & 100 & 0.85 & 2.2 \\
Vegetative wetland & 1.0 & 0.2 & 0.25 & 0.5 & 0.12 & 4.0 & 0.2 & 10 & 0.5 & 100 & 0.85 & 5.5 \\
\hline
\end{tabular}

$a$ : Canopy storage [mm], bl: Storage interception coefficient [-], P: Free throughfall coefficient [-], $S$ : Canopy field capacity $[\mathrm{mm}], K$ : Canopy drainage rate coefficient $[\mathrm{mm} / \mathrm{h}], b 2$ : Canopy drainage exponential parameter $\left[\mathrm{mm}^{-1}\right], A l$ : Surface albedo [-], $h$ : Vegetation height $[\mathrm{m}], K t$ : Optical transmission coefficient [-], Rs: Canopy average stomatal resistance [s/m], V: Vegetation fraction [-]; LAI: Canopy leaf area index [-]. For details, refer to Ivanov et al. [2004b].

Table 4. The median values of total monthly precipitation $(\operatorname{Pr},[\mathrm{mm}])$, runoff $(R f,[\mathrm{~mm}])$, evapotranspiration $(E T,[\mathrm{~mm}])$, and mean monthly soil moisture content averaged over the top 100 $\mathrm{mm}$ of soil column (SM, [\%]) for 300 years of simulations of Manchester basin dynamics, for the historic (CTL) and future (FUT) periods, for the months of May (6 left columns) and August (6 right columns). Ten, 30-year long trajectories were projected for the three weather station locations in Detroit, Lansing, and Toledo.

\begin{tabular}{|c|c|c|c|c|c|c|c|c|c|c|c|c|}
\hline & \multicolumn{2}{|c|}{ Detroit } & \multicolumn{2}{|c|}{ Lansing } & \multicolumn{2}{|c|}{ Toledo } & \multicolumn{2}{|c|}{ Detroit } & \multicolumn{2}{|c|}{ Lansing } & \multicolumn{2}{|c|}{ Toledo } \\
\hline & CTL & FUT & CTL & FUT & CTL & FUT & CTL & FUT & CTL & FUT & CTL & FUT \\
\hline$P r$ & 76.68 & 96.73 & 62.64 & 73.79 & 69.74 & 66.63 & 89.47 & 83.88 & 82.38 & 79.47 & 73.60 & 71.00 \\
\hline$R f$ & 13.62 & 19.14 & 9.60 & 7.64 & 11.01 & 6.91 & 6.50 & 1.17 & 3.18 & 0.41 & 4.07 & 0.59 \\
\hline$E T$ & 67.15 & 81.24 & 66.29 & 80.19 & 68.26 & 83.18 & 74.83 & 96.67 & 71.14 & 92.68 & 70.48 & 90.77 \\
\hline$S M$ & 85.70 & 85.80 & 84.33 & 82.74 & 85.27 & 83.68 & 81.64 & 78.18 & 78.92 & 75.59 & 80.29 & 76.91 \\
\hline
\end{tabular}




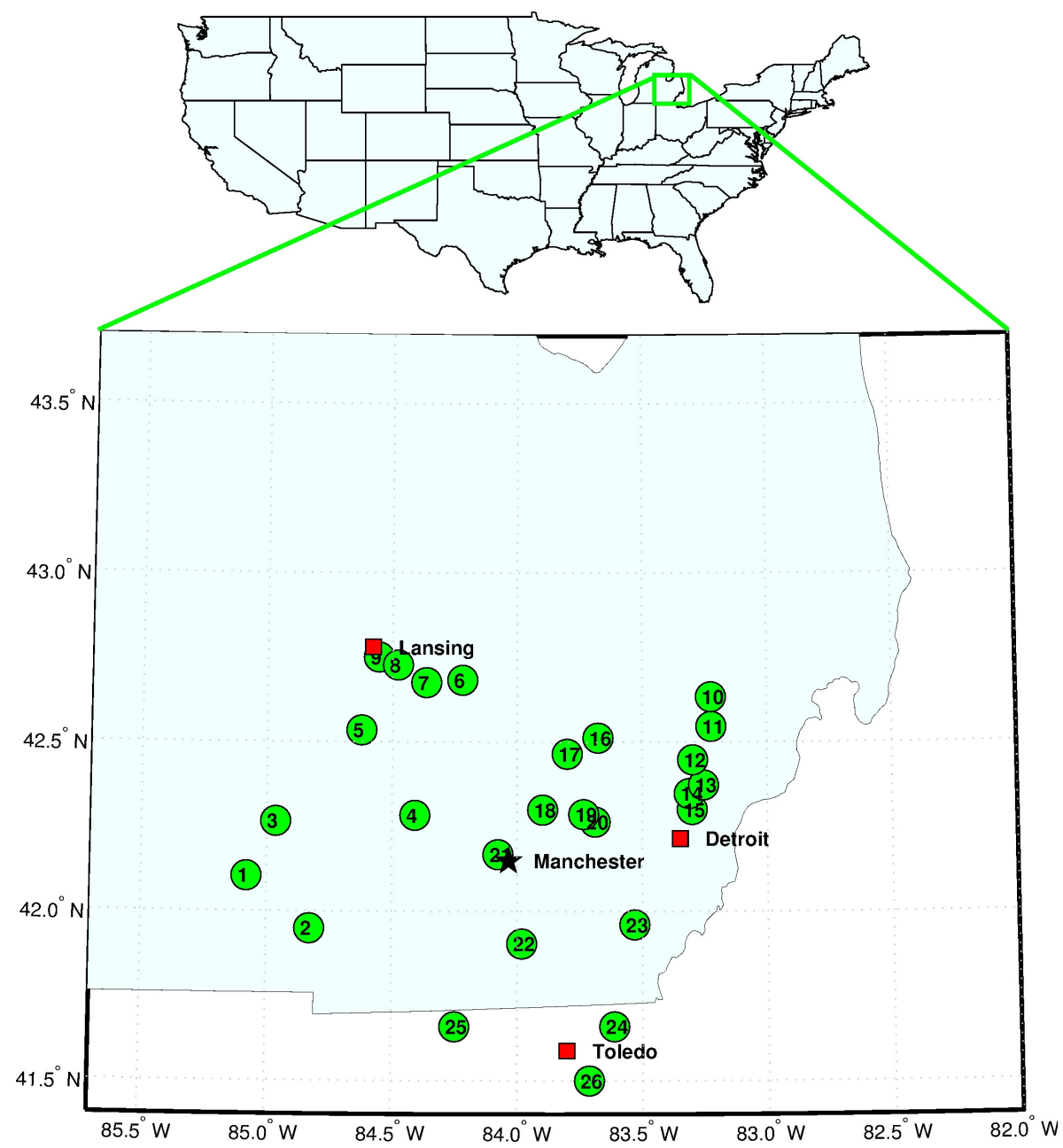

Fig. 1. The locations of the Manchester watershed, MI, USA (black star), 3 meteorological stations in Detroit, MI, Lansing, MI, and Toledo, OH (red squares), and 26 USGS stream gauges (green circles) (See Table 1).
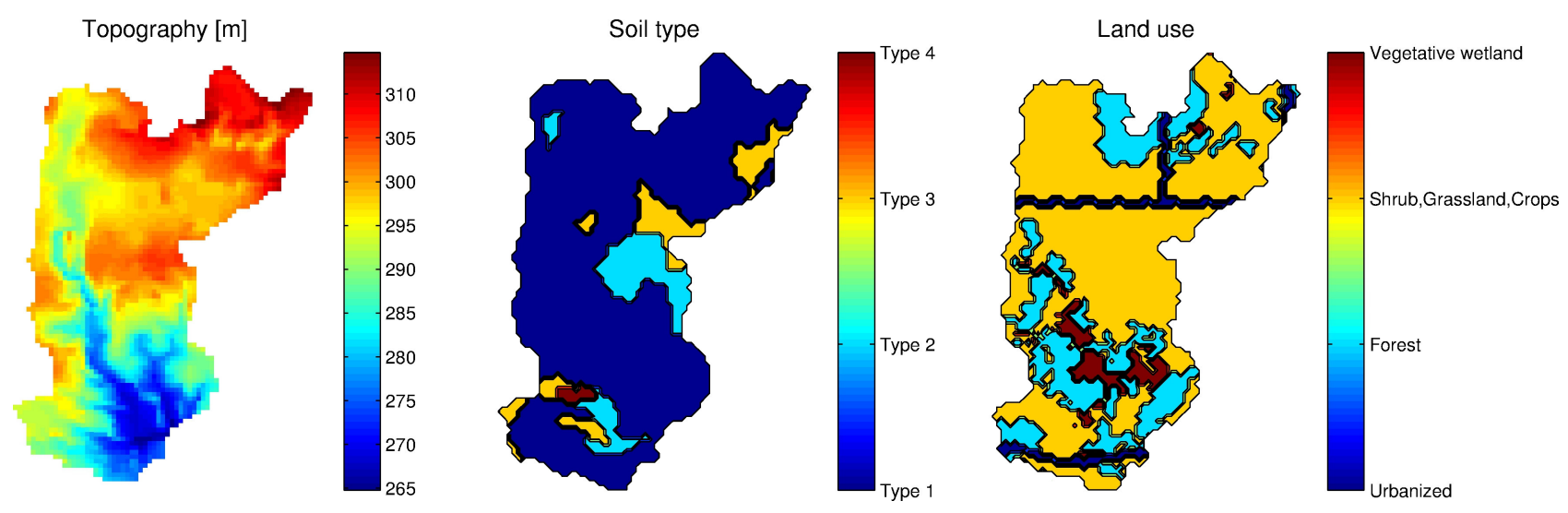

Fig. 2. The spatial distributions of elevation, soil type (Table 2), and land use (Table 3) in the Manchester watershed. 

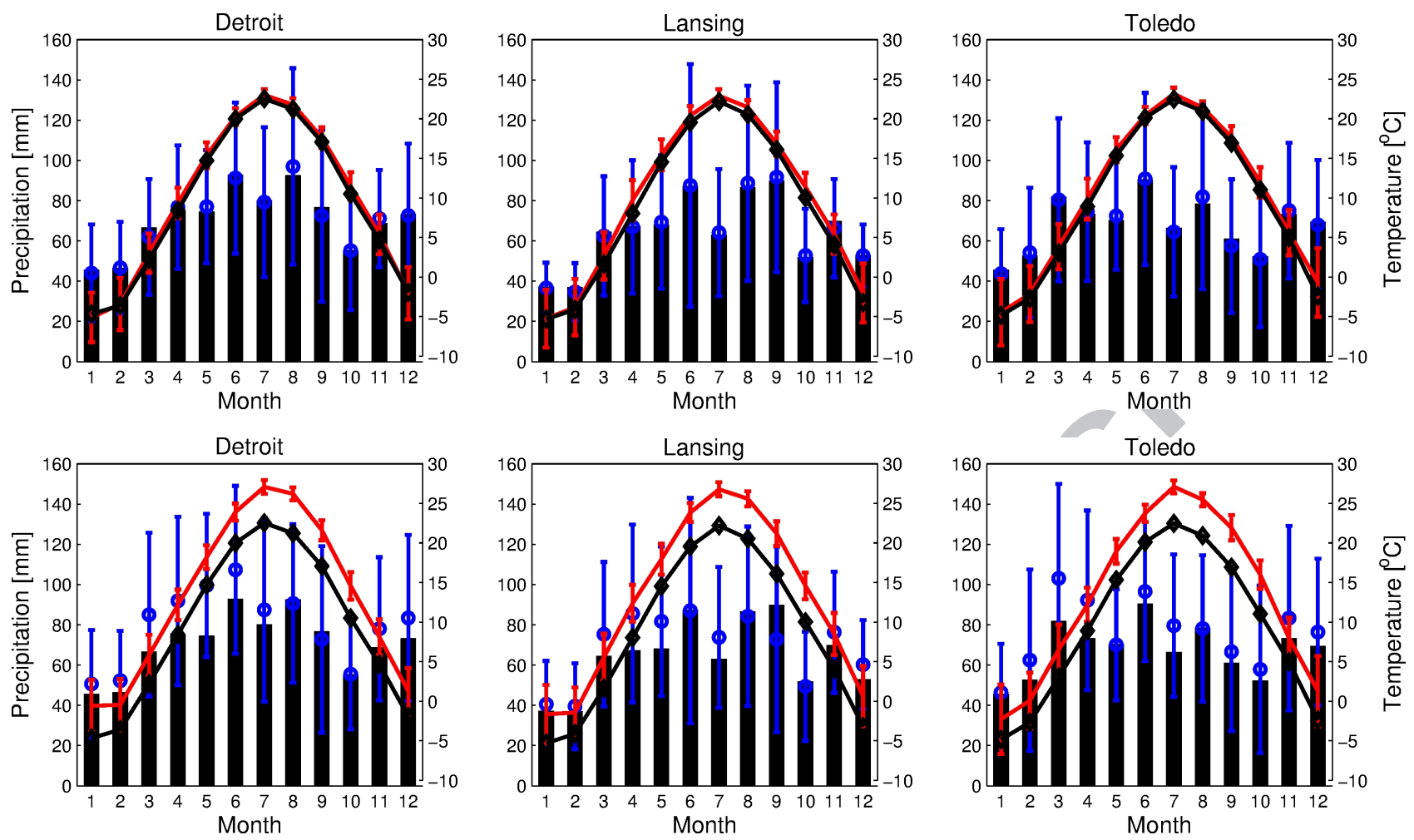

Fig. 3. Mean monthly observed and AWE-GEN simulated precipitation and temperature for the meteorological stations of Detroit, Lansing, and Toledo. The top subplots correspond to the control period, $1961-1990$, while the bottom subplots refer to the future period, $2081-2100$. The left axis of each subplot is for precipitation, while the right one is for temperature. The black bars and the blue circles with errorbars represent the observed and simulated mean monthly precipitation, respectively. The black lines with diamonds and red errorbars represent the observed and simulated mean monthly temperature, respectively. The simulated variables and their respective errorbars represent the mean and the standard deviation for 300 monthly variables over 300 years of weather series generated with AWE-GEN. 
(a) Annual
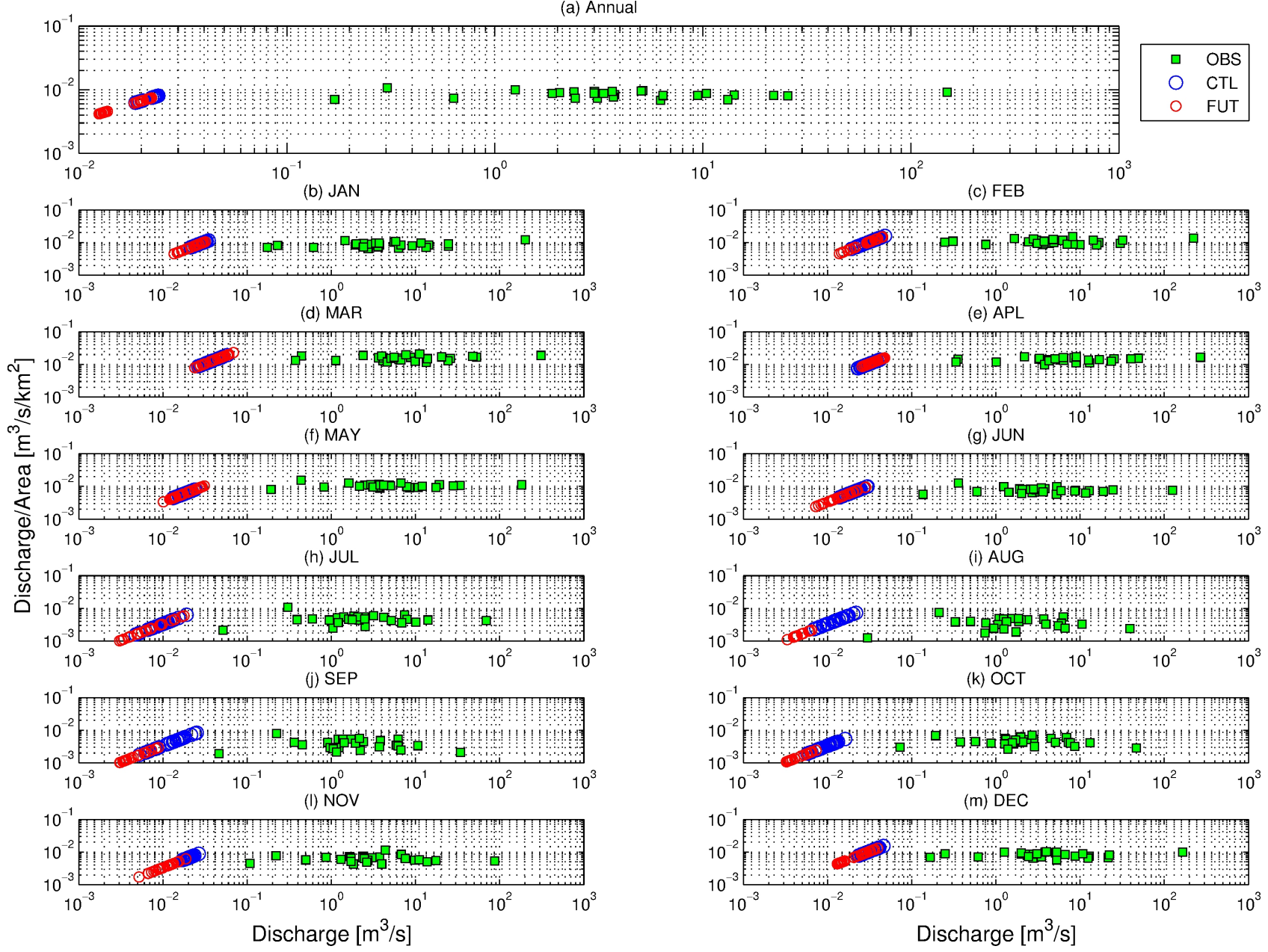

Fig. 4. The mean annual and monthly specific discharge (mean volumetric discharge normalized by the watershed area, Y-axis) in relation to the mean discharge over respective time interval (X-axis) for 26 USGS gauge locations (green squares, "OBS") and the Manchester watershed: the historic period of 1961 - 1990 (blue circles, "CTL") and the simulation results for the future period, 2081 2100 (red circles, "FUT"). The annual discharge is used in the top subplot (a), while monthly values are used in the rest of subplots (b) to (m). The observed specific discharge is for the years specified in Table 1, while the simulated discharge is computed by averaging over each ensemble period of 30 years. For each of the three weather station locations, 10 ensemble time series are used and thus the number of the blue and red circles is 30 each. 

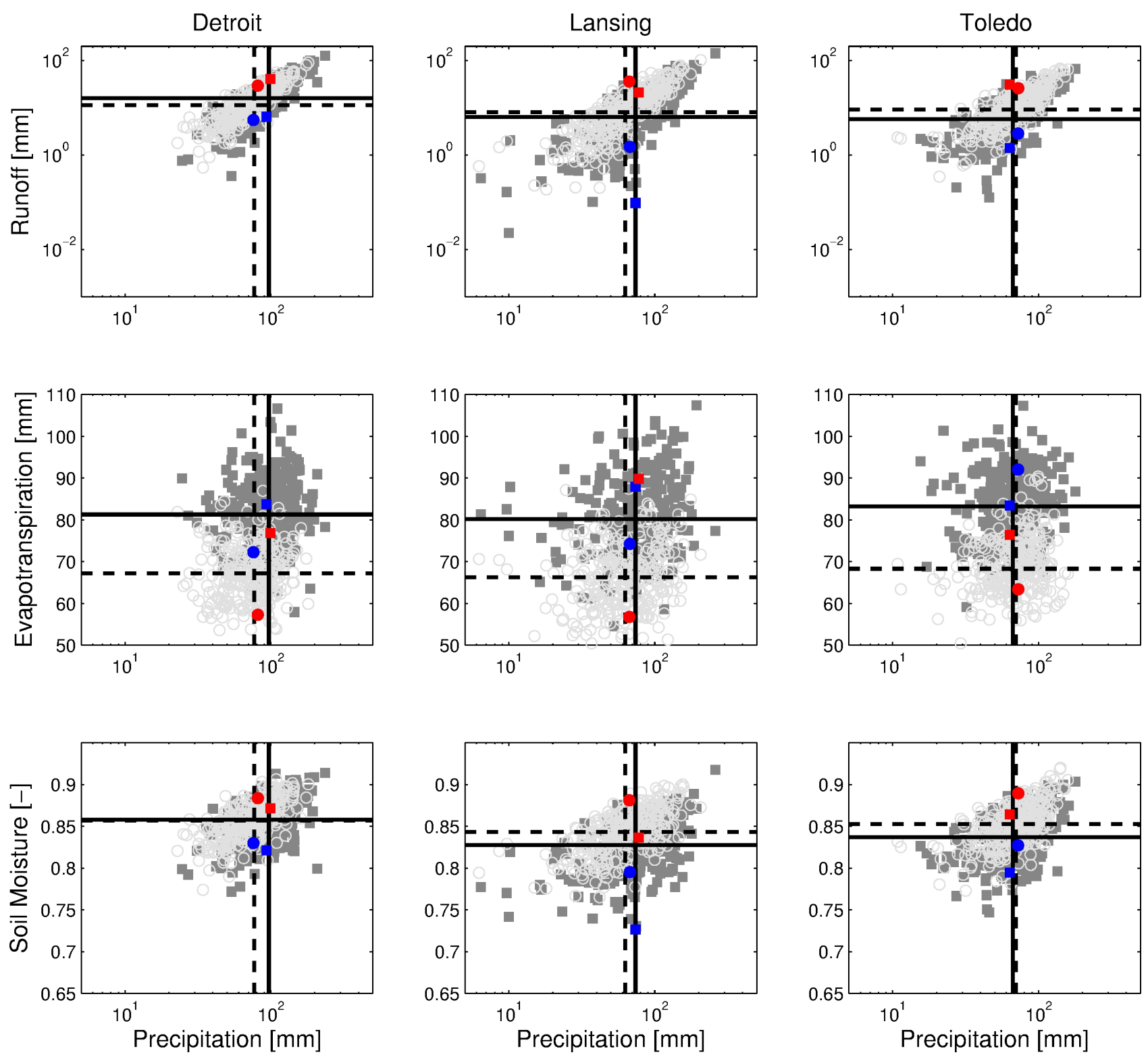

Fig. 5. Spatially averaged total monthly runoff and evapotranspiration and mean monthly soil moisture content averaged over the top $100 \mathrm{~mm}$ of soil column in relation to monthly total precipitation for 300 years of simulated future conditions for the 3 locations of meteorological stations in Detroit, Lansing, and Toledo. The results are shown only for the month of May. The light grey circles representing 300 simulation points correspond to the control period while the darker grey squares represent the future period. The dashed (solid) black lines correspond to the median values for the control (future) periods (the actual values are reported in Table 4). Both for the control and future periods, two years out of 300 are identified: their precipitation in May is approximately equal to the median precipitation in May, but show different runoff volume, which is either minimum (blue) or maximum (red) for that value of precipitation (illustrated as circles (control) and squares (future)). 

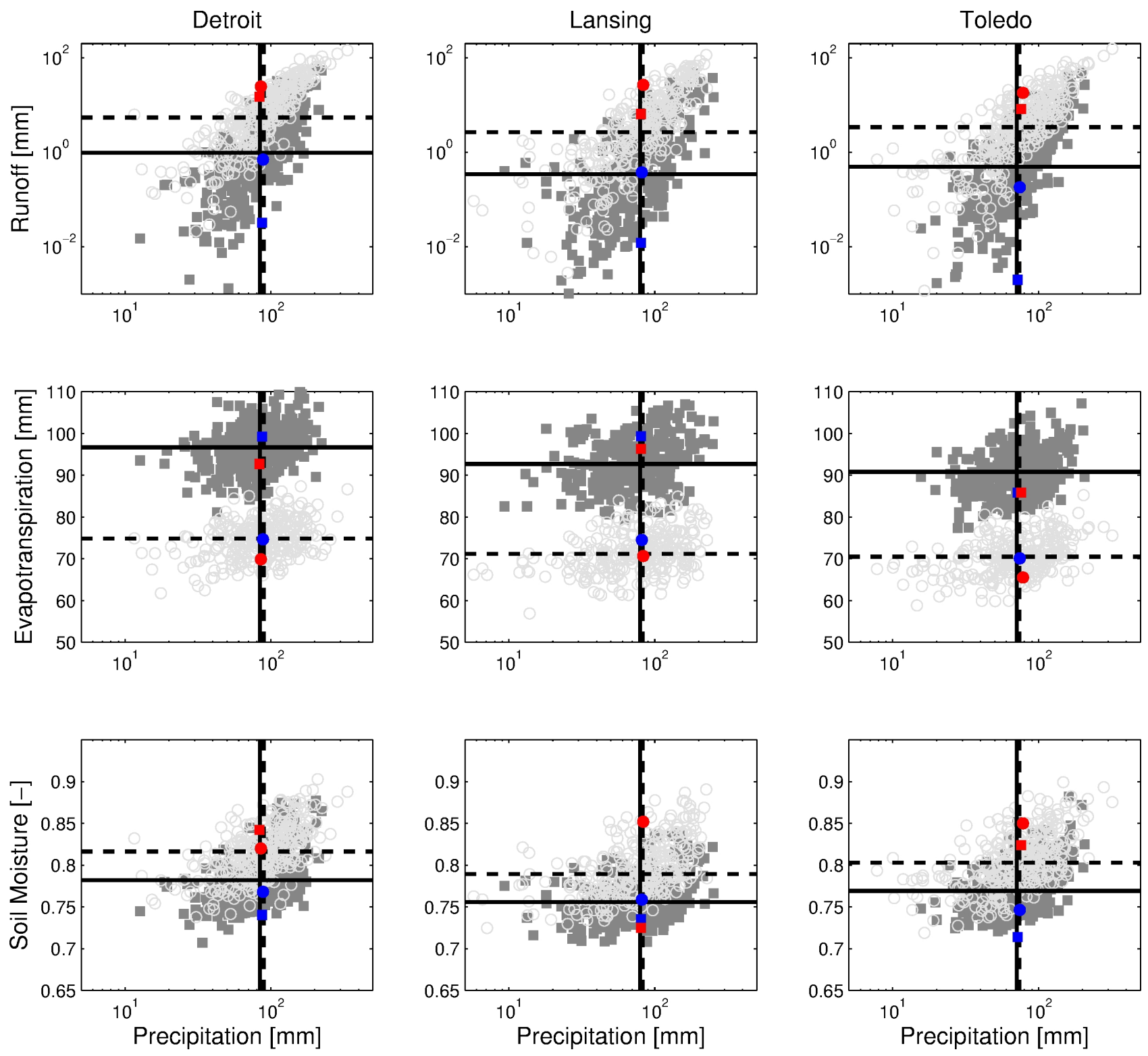

Fig. 6. Spatially averaged total monthly runoff and evapotranspiration and mean monthly soil moisture content averaged over the top $100 \mathrm{~mm}$ of soil column versus monthly total precipitation for 300 years of simulated future conditions for the 3 locations of meteorological stations in Detroit, Lansing, and Toledo. The results are shown only for the month of August. The light grey circles representing 300 simulation points correspond to the control period while the darker grey squares represent the future period. The dashed (solid) black lines correspond to the median values for the control (future) periods (the actual values are reported in Table 4). Both for the control and future periods, two years out of 300 are identified: their precipitation in August is approximately equal to the median precipitation in August, but show different runoff volume, which is either minimum (blue) or maximum (red) for that value of precipitation (illustrated as circles (control) and squares (future)). 
(a) Depth [mm]

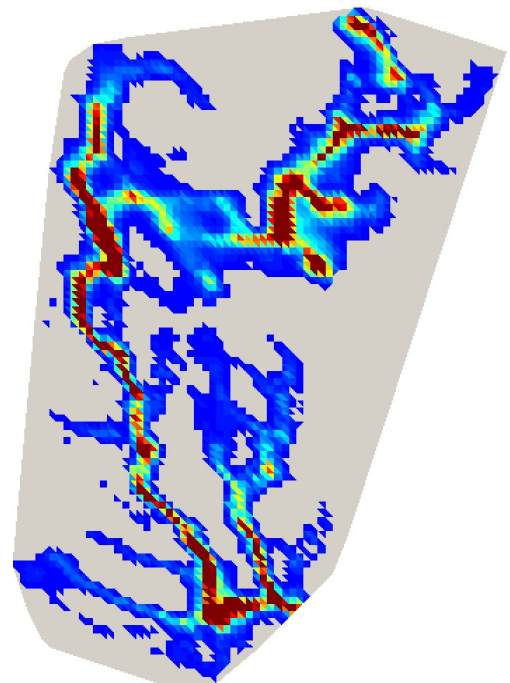

(d) Depth [mm]

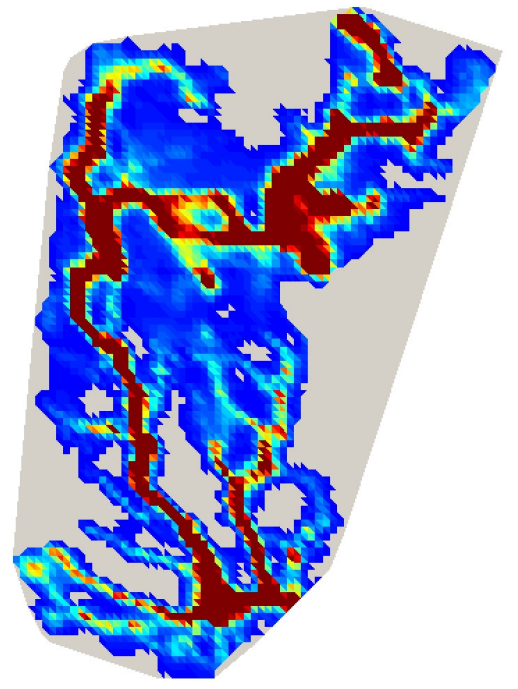

(b) Velocity $[\mathrm{m} / \mathrm{s}]$

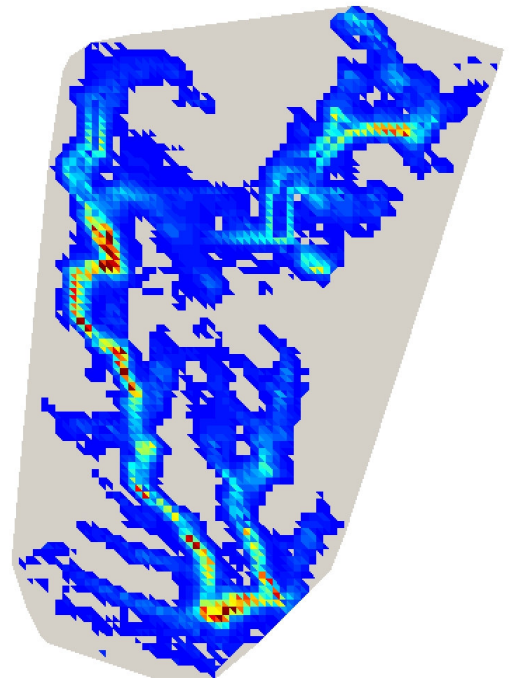

(e) Velocity $[\mathrm{m} / \mathrm{s}]$

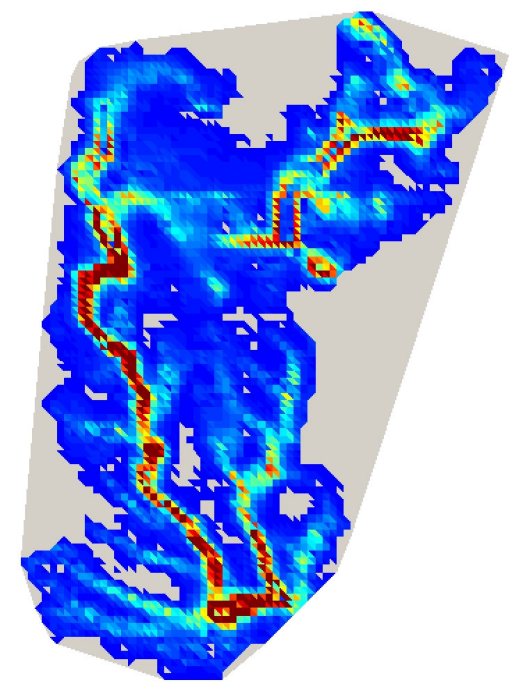

(c) Shear stress $\left[\mathrm{kg} / \mathrm{m} / \mathrm{s}^{2}\right]$

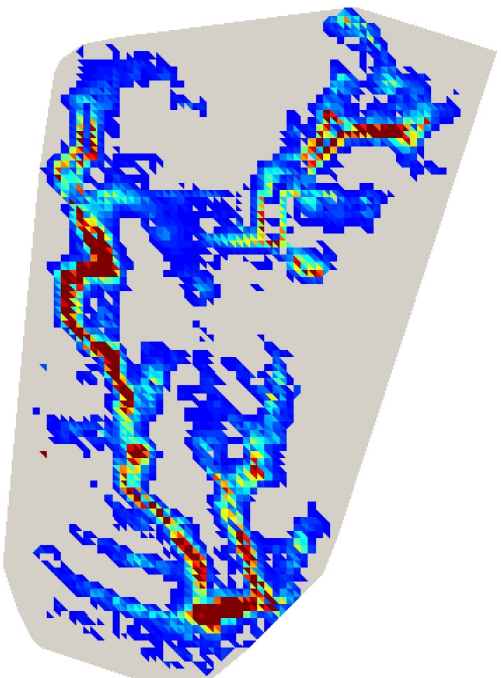

(f) Shear stress $\left[\mathrm{kg} / \mathrm{m} / \mathrm{s}^{2}\right]$

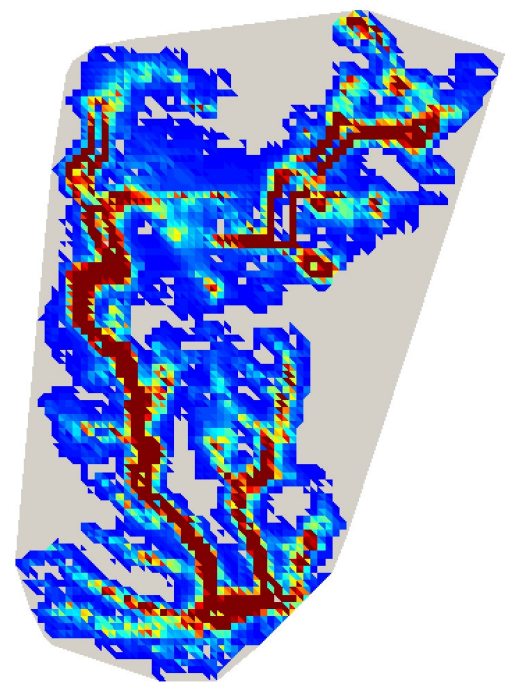

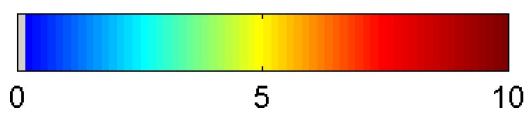
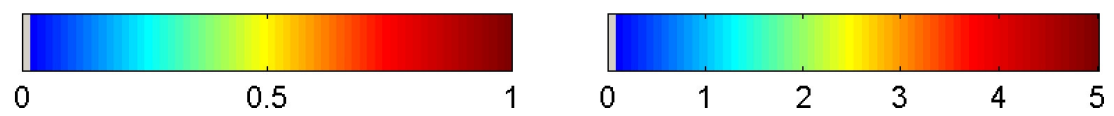

Fig. 7. The spatial distributions of flow depth, velocity, and shear stress for the two years that have the same total monthly precipitation (corresponding to the median of 300 years) for the month of May, for the location of Detroit (the control period). These instantaneous spatial distributions are obtained for the peak flow time during the simulated month of May. The top panel corresponds to the "min" year (blue circles in Fig. 5, the peak flow is $0.086 \mathrm{~m}^{3} / \mathrm{s}$ ), while the bottom panel is for the "max" year of the two runoff cases (red circles in Fig. 5, the peak flow is $0.992 \mathrm{~m}^{3} / \mathrm{s}$ ). 

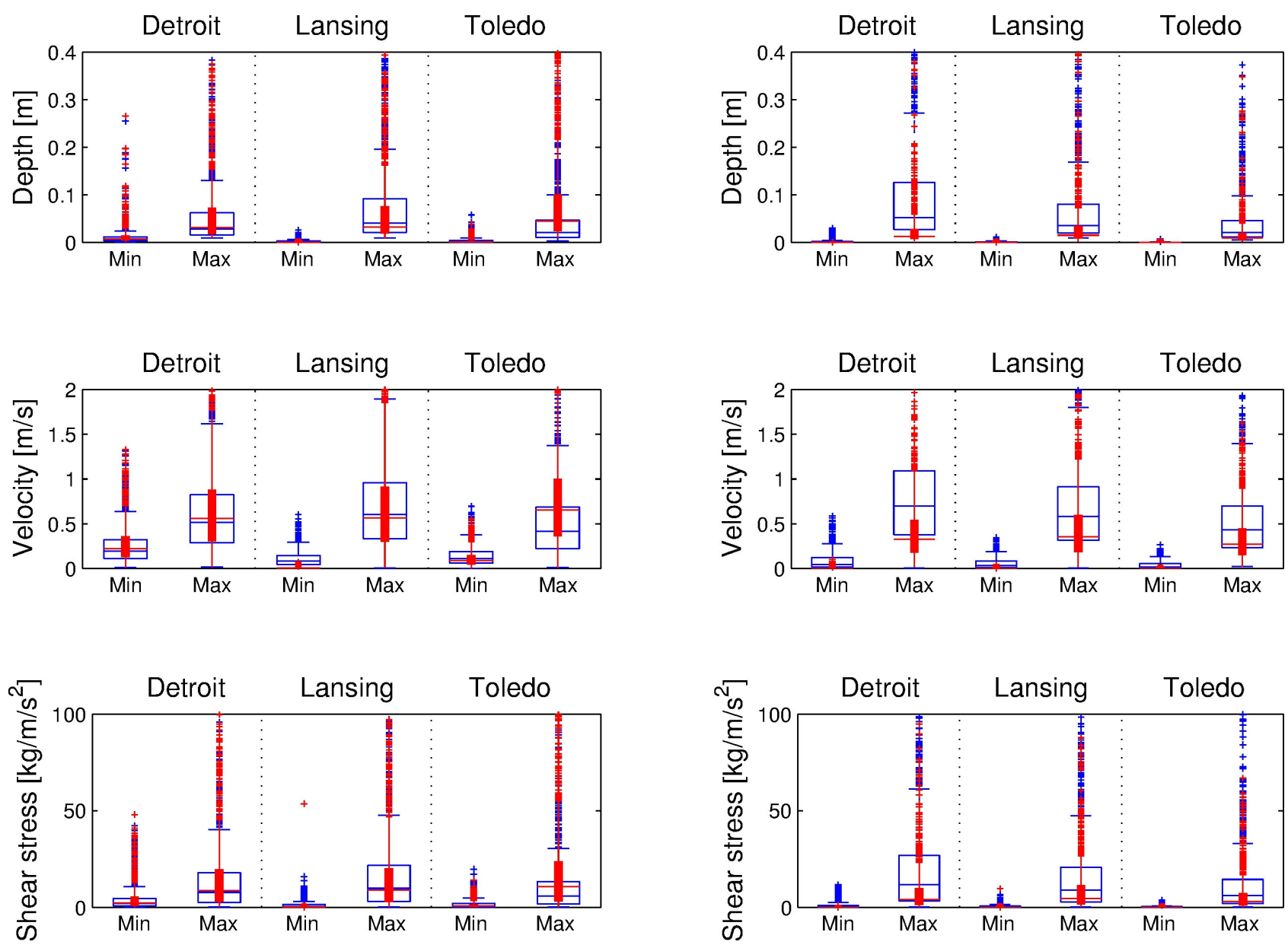

Fig. 8. Boxplots of depth, velocity, and shear stress averaged for a fixed region of stream network approximated as internal cells with depths greater than $10 \mathrm{~mm}$ for the flow case illustrated in Fig. 7(d). The blue boxplots (empty boxes of thicker widths) refer to the control (CTL), while the red boxplots (thin filled boxes) correspond to the future (FUT) period. In each boxplot, the central mark is the median, the edges of the box are the 25th and 75th percentiles of the values identified within the fixed region of stream network, and the whiskers are drawn as outliers smaller or larger than 1.5 times the interquartile range from the 25 th or 75 th percentiles. The " $m i n$ " and "max" refer to the minimum (blue in Fig. 5 and 6) and maximum (red in Fig. 5 and 6) of runoff scenarios, as illustrated in Fig. 5 and 6. The left panel of subplots corresponds to the month of May, while the right panel of subplots is for August. 
(a) Detroit, May

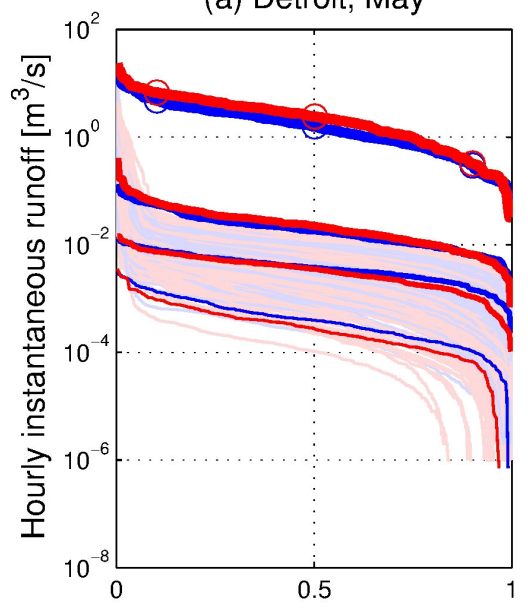

(d) Detroit, Aug.

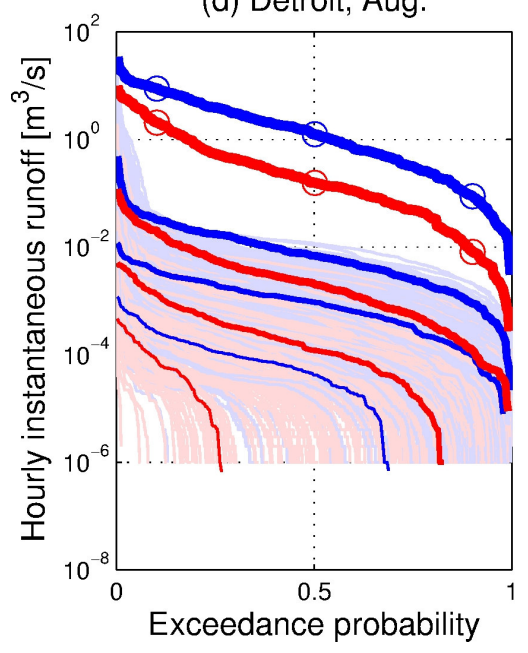

(b) Lansing, May

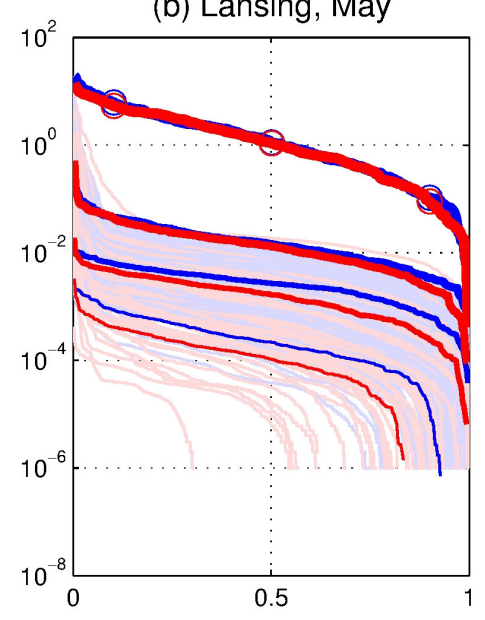

(e) Lansing, Aug.

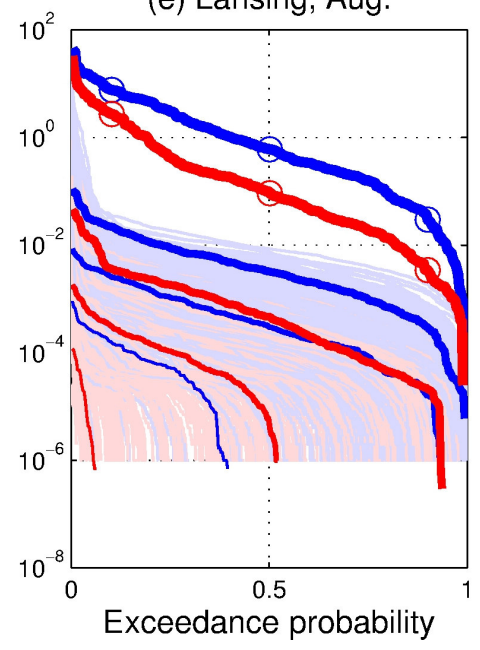

(c) Toledo, May
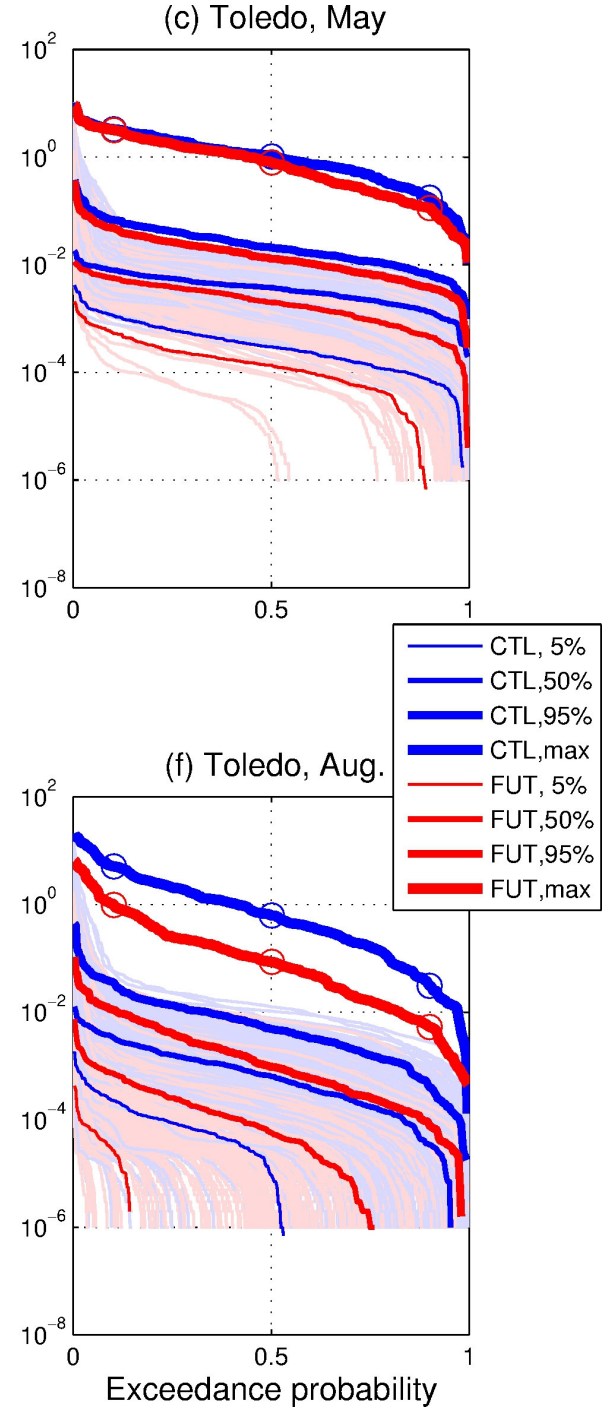

Fig. 9. Runoff duration curves of spatially-averaged runoff instantaneous runoff rates for (a) Detroit, the month of May, (b) Lansing, May, (c) Toledo, May, (d) Detroit, Aug., (e) Lansing, Aug., and (f) Toledo, Aug. The blue color corresponds to the control period (CTL), while the red color corresponds to the future (FUT) period. The light blue and red curves (300 lines in total) refer to monthly runoff duration curves obtained from the hourly instantaneous runoff rates for the 300 ensemble months. Hourly runoff rates corresponding to 5/50/95 percentiles of non-exceedance probability and the maximum of each runoff duration curve are obtained and plotted as ' $5 \%$ ', '50\%', '95\%', and 'max' curves in solid blue and red colors. They represent the monthly low, median, high, and maximum monthly hydrologic conditions. The flows corresponding to the 10, 50, and 90 nonexceedance percentiles (denoted as circles on the thickest blue and red lines) are used to obtain characterization of hydraulic conditions in Fig. 10. 


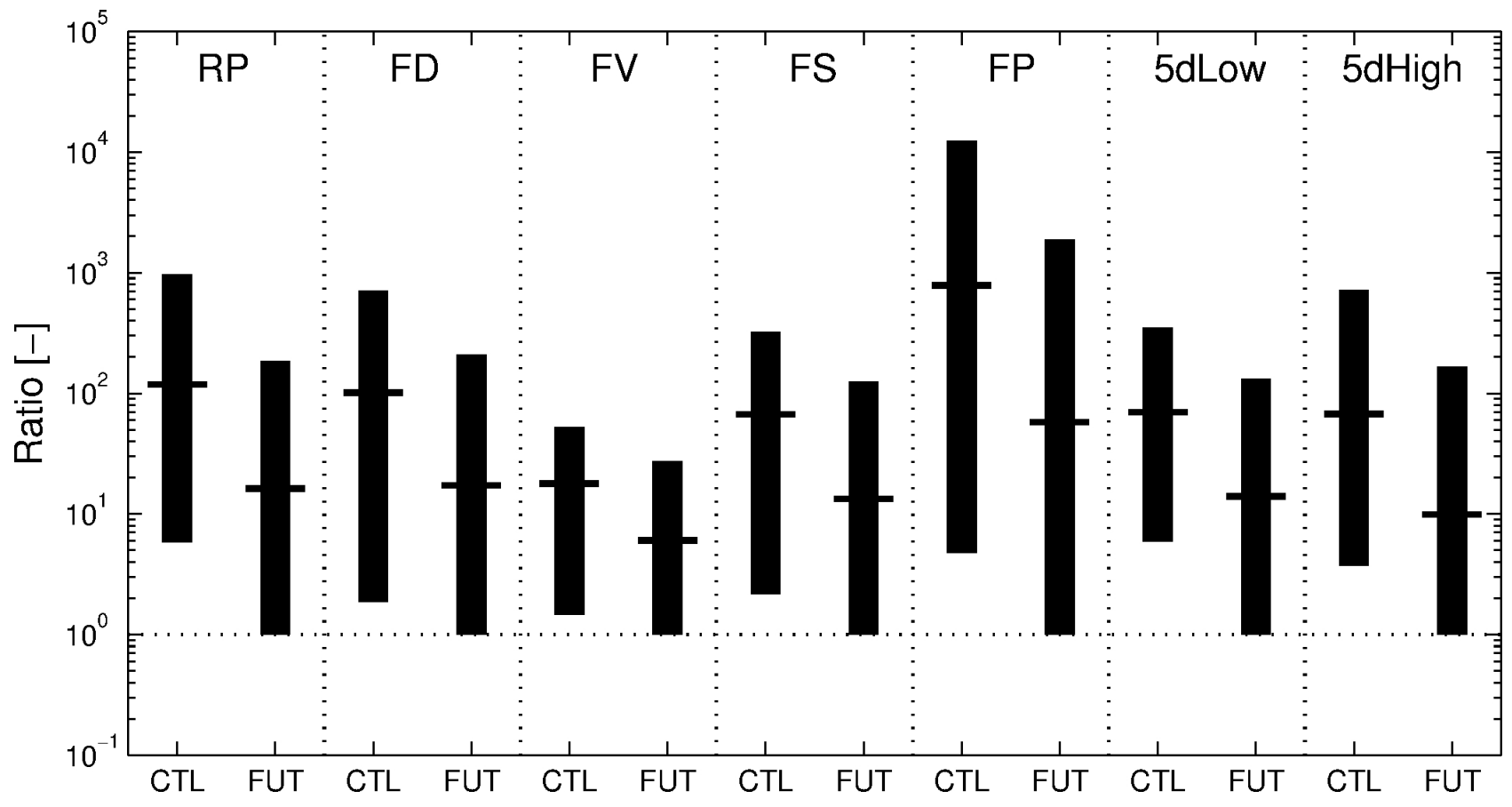

Fig. 10. Ratios of the first five metrics corresponding to 3 selected instances of runoff rate (i.e., denoted as circles on the thickest blue and red lines in Fig. 9-(f)) for the control (CTL) and future (FUT) periods. The last two metrics (5dLow and 5dHigh) represent the ratios of the values corresponding to the 10,50 , and 90 th percentiles of 300, 5-day mean low/high flows, respectively. For each of the variables, the ratio is computed by dividing the three percentile values by the value corresponding to 10th percentile of FUT case. The low (high) edge of each bar refers to the ratio for the 10th (90th) percentile, while the middle line refers to the ratio for the 50th percentile. As seen, the low bar edge for FUT corresponds to unity, thereby serving as a reference. The first five variables are runoff peak $(R P)$, the "stream-network" averaged flow depth $(F D)$, flow velocity $(F V)$, and flow shear stress $(F S)$ of the flow peak $(F P)$, and flow peak discharge $(F P)$ simulated at the outlet and corresponding to a given $R P$. The results are for the case of the month of August, the location of Toledo (Fig. 9-(f)). 